2001s-30

\title{
Contracting under Ex Post Moral Hazard and Non-Commitment
}

M. Martin Boyer

Série Scientifique
Scientific Series

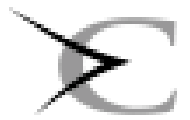

Montréal

Avril 2001 


\section{CIRANO}

Le CIRANO est un organisme sans but lucratif constitué en vertu de la Loi des compagnies du Québec. Le financement de son infrastructure et de ses activités de recherche provient des cotisations de ses organisationsmembres, d'une subvention d'infrastructure du ministère de la Recherche, de la Science et de la Technologie, de même que des subventions et mandats obtenus par ses équipes de recherche.

CIRANO is a private non-profit organization incorporated under the Québec Companies Act. Its infrastructure and research activities are funded through fees paid by member organizations, an infrastructure grant from the Ministère de la Recherche, de la Science et de la Technologie, and grants and research mandates obtained by its research teams.

\section{Les organisations-partenaires / The Partner Organizations}

•École des Hautes Études Commerciales

-École Polytechnique

-Université Concordia

-Université de Montréal

-Université du Québec à Montréal

-Université Laval

-Université McGill

-MEQ

-MRST

-Alcan inc.

-AXA Canada

-Banque du Canada

- Banque Laurentienne du Canada

-Banque Nationale du Canada

-Banque Royale du Canada

-Bell Québec

-Bombardier

-Bourse de Montréal

-Développement des ressources humaines Canada (DRHC)

-Fédération des caisses populaires Desjardins de Montréal et de l'Ouest-du-Québec

-Hydro-Québec

-Imasco

-Industrie Canada

-Pratt \& Whitney Canada Inc.

-Raymond Chabot Grant Thornton

-Ville de Montréal

(C) 2001 M. Martin Boyer. Tous droits réservés. All rights reserved.

Reproduction partielle permise avec citation du document source, incluant la notice $\odot$.

Short sections may be quoted without explicit permission, if full credit, including $\odot$ notice, is given to the source.

Ce document est publié dans l'intention de rendre accessibles les résultats préliminaires

de la recherche effectuée au CIRANO, afin de susciter des échanges et des suggestions.

Les idées et les opinions émises sont sous l'unique responsabilité des auteurs, et ne représentent pas nécessairement les positions du CIRANO ou de ses partenaires.

This paper presents preliminary research carried out at CIRANO and aims at encouraging discussion and comment. The observations and viewpoints expressed are the sole responsibility of the authors. They do not necessarily represent positions of CIRANO or its partners. 


\title{
Contracting under Ex Post Moral Hazard and Non-Commitment ${ }^{*}$
}

\author{
M. Martin Boyer
}

\section{Résumé / Abstract}

Ce document de travail caractérise le contrat optimal dans une économie où un agent informé de l'état de la nature doit rapporter cet état à un principal qui ne peut se commettre de manière crédible dans une stratégie de vérification de l'annonce de l'agent. Puisque le principal ne peut se commettre, il devient optimal pour l'agent de mentir avec une certaine probabilité. En supposant qu'il existe $\mathrm{T}>1$ pertes possibles en cas d'accident, que l'agent ne peut feindre un accident (il est restreint à rapporter la perte en cas d'accident, mais la présence d'un accident est une information de nature commune), le contrat optimal est tel que les hautes pertes sont sur-indemnisées alors que les faibles pertes sont sous-indemnisées en moyenne. Le niveau de sur-indemnisation des hautes pertes diminue toutefois avec la perte elle-même. Le contrat optimal peut ainsi être représenté comme une simple combinaison d'une franchise, d'un paiement forfaitaire et de co-paiements.

This paper characterizes the optimal insurance contract in an environment where an informed agent can misrepresent the state of the world to a principal who cannot credibly commit to an auditing strategy. Because the principal cannot commit, the optimal strategy of the agent is not to tell the truth all the time. Assuming that there are $T>1$ possible losses, and that the agent cannot fake an accident (he is constrained only to misreport the size of the loss when a loss occurs), the optimal contract is such that higher losses are over-compensated while lower losses are on average under-compensated. The amount by which higher losses are over-compensated decreases as the loss increases. The optimal contract may then be represented as a simple combination of a deductible, a lump-sum payment and a coinsurance provision.

Mots Clés : Absence d'engagement, assurance, aléa moral ex post, théorie des contrats

Keywords: Non-commitment, insurance, ex post moral hazard, contract theory

JEL: D82, G2, C72

\footnotetext{
* Corresponding Author: M. Martin Boyer, CIRANO, 2020 University Street, 25 ${ }^{\text {th }}$ floor, Montréal, Qc, Canada H3A 2A5 Tel.: (514) 985-4000 Fax: (514) 985-4039 email: martin.boyer@hec.ca I would like to thank my dissertation committee Stanley Baiman, David Cummins, Georges Dionne, Neil Doherty and Sharon Tennyson (supervisor) for their insights, as well as Keith Crocker, Steve Coate, Richard Derrig, Michele Piccone and Pascale Viala. The financial help received during my doctoral studies from the SSHRC of Canada and the S.S. Huebner Foundation are gratefully acknowledged. I also acknowledge the continuing financial support of CIRANO and of the Risk Management Chair at HEC. I am responsible for all remaining errors.
}

† École des Hautes Études Commerciales and CIRANO 


\section{Introduction}

\subsection{Motivation}

In many economic settings agents have privileged information concerning the state of the world. An agent who must report the state of the world to a principal is faced with was is known as ex post moral hazard: he may want to misreport the state to extract rents. The problem for the principal is to design a contract that incorporates the agent's reporting behavior. ${ }^{1}$

The goal of this paper is to characterize the optimal insurance contract when an agent ${ }^{2}$ can misrepresent his loss when involved in an accident. I present the problem from an insurance fraud point of view, although the extension to income-tax fraud and other ex post moral hazard situations is straightforward. The focus is on what is known as insurance fraud build-up because it appears to be the most costly type of insurance fraud. ${ }^{3}$ In this type of fraud, agents do not fake accidents, they only fake injuries. This means that the occurrence of an accident is common knowledge. The agent involved in an accident must decide whether to report his true loss, an information that is private to him, to the insurer or whether to exaggerate it. The moral hazard problem occurs because the agent may not want to tell the insurer the truth. The insurer must then decide whether or not to audit the agent's report. My approach differs from the past literature in that the principal-agent problem is not solved because of the insurer's inability to commit to an auditing strategy. This inability to commit is the main driving force of the results.

The results of this paper are three-fold. First, if the insurer cannot commit to an auditing strategy, then there exists a Perfect Bayesian Nash Equilibrium of the so-called claiming game which has the characteristic that only one type of agent (type $\lambda_{t^{*}}$, say) ever plays a mixed strategy involving telling the truth and exaggerating his loss. The solution also has the property that the insurer 1- never audits reports less than or equal to $\lambda_{t^{*}}$, and 2- plays a mixed strategy between auditing and not auditing reported losses greater than $\lambda_{t^{*}}$.

The second result is that the optimal contract is such that higher losses are over-compensated while lower losses are on average under-compensated. The levels of under- and over-compensation are such that the agent receives the same expected marginal utility whether he is involved in an accident or not. This is not to say that he gets the same marginal utility in every state of the world; rather, an agent involved in an accident expects his marginal utility to be equal to his marginal

\footnotetext{
${ }^{1}$ An ex post moral hazard approach has been used to study income-tax fraud, where the agent privately knows what was his income in the last fiscal year, and to insurance fraud, where the agent privately knows what loss he suffered in a given accident.

${ }^{2}$ The terms policyholder and agent are used as synonyms in the paper, as are the terms insurer and principal. The insurer/principal is a she, while the policyholder/agent is a he.

${ }^{3}$ There are four types of insurance fraud as reported by Hoyt (1989), including insurance fraud build-up. The Insurance Research Council estimates that $90 \%$ of all excessive insurance payments are due to build-up
} 
utility when he is not involved in an accident. The third result is that the amount by which higher losses are over-compensated decreases as the loss increases.

The optimal contract I find does not claim to eliminate fraud; there will still be fraud in equilibrium. What the paper presents is a contract that mitigates the costs of insurance fraud. In a sentence, this paper reexamines the contract design under costly state verification with the assumption that the insurer cannot commit credibly to an auditing strategy. A very interesting aspect of the optimal contract I derive is that it may be represented as a combination of a deductible, a lump-sum payment and a coinsurance provision. This contradicts the popular view that deductible and coinsurance provisions are not optimal ways to control insurance fraud.

\subsection{Past Literature}

The literature on the design of optimal contracts is extensive. It is well known in a competitive setting, given no asymmetric information and no insurance loading, that agents choose a contract that gives them the same utility in all states of the world. This property is known as perfect income smoothing. When information is asymmetric, then the optimal contract may no longer provide perfect income smoothing.

In the case of the insurance market, the relationship between all parties to a contract is best modeled as a principal-agent relationship where the agent has private information (see Ross, 1973, and Holmstrom, 1979). The problem is then to design a contract that optimizes one player's maximization function subject to every players' incentives. There are three main types of asymmetric information in this context: adverse selection, ex ante moral hazard and ex post moral hazard. Ex post moral hazard is the proper way to model insurance fraud build-up.

Spence and Zeckhauser (1971) were the first to recognize the difference between moral hazard ex ante and ex post. ${ }^{4}$ They showed that if audits can be conducted at no cost, the principal will audit every claim, while if audits are not feasible, then the insurer will never audit. Therefore, either everyone is audited at no cost to the insurer, or no one is audited. The authors then concluded that there was no difference between ex ante and ex post moral hazard. They did not, however, study the case of partial monitoring at a price. Townsend (1979) was the first to develop a formal model that includes partial auditing at a cost.

Townsend sets up a world where the agent who has private information as to the state of the world must reveal that information to the insurer. The insurer who does not know if the information revealed by the agent is truthful can verify that information by paying a monitoring fee. In Townsend's world, the insurer can commit to a deterministic auditing strategy (either you

\footnotetext{
${ }^{4}$ See Arnott (1992) and Winter (1992) for a survey of the moral hazard literature.
} 
audit all losses of a given type with probability one or you never audit). The optimal auditing strategy will then entail a cutoff rule where the insurer audits all losses above a cutoff point, and does not audit losses below. ${ }^{5}$ In this economy there is no fraud since the contract is incentive compatible and the insurer's commitment to the audit strategy is complete. All the literature that followed Townsend's basic setup (i.e.: insurer's ability to audit at a cost) is known as the costly state verification (CSV) literature.

Other authors such as Mookherjee and Png (1987), Scotchmer (1987), Sanchez and Sobel (1993), and more recently Bond and Crocker (1997) developed Townsend's basic approach in more details. Using the same setup as Townsend, Mookherjee and Png showed that stochastic auditing was superior to deterministic auditing because truth-telling can still be achieved using stochastic auditing, and because it was less costly than deterministic auditing. Bond and Crocker showed that the optimal contract in the CSV literature with commitment was such that the agent is fully insured in the audited states of the world (minus a deductible), but received a flat payment in the no-auditing states of the world.

The drawback of all these papers, where the principal can commit, is that they do not seem to describe reality. In the economy, we observe income-tax fraud and insurance fraud. This means that truth-telling is not always the optimal strategy of the agents. Possible explanations are that the principal is not sophisticated enough to apply the literature's truth-telling contract, or that such contracts are based on incorrect assumptions. One such assumption is the principal's commitment to an auditing strategy.

Picard (1996) and Boyer (1998) study this commitment problem. They construct a simple twostate model where truth-telling is not always achieved because of the insurer's inability to commit credibly ex ante to an audit strategy ex post. This means that, in equilibrium, some agents commit fraud and are successful at it. Similar models were derived by Graetz, Reinganum and Wilde (1986) and Sanchez and Sobel (1993) in the income-tax literature. Both papers find that there are agents who successfully defraud the government, and ultimately pay less taxes than they were supposed to. Khalil (1997) approaches the same problem from the standpoint of a regulator who cannot commit to an auditing strategy of a monopolist's cost (basically the model of Baron and Myerson, 1981). Finally Persons (1997) and Khalil and Parigi (1998) study the problem of commitment in debt contracts.

The remainder of the paper is organized as follows. The next section presents the model, with its assumptions. In section 3 I develop the model by presenting the function to maximize, as well

\footnotetext{
${ }^{5}$ This contract resembles the debt contract obtained by Gale and Hellwig (1985) and Dionne and Viala (1992). See also Holmstrom (1979), Baiman and Demski (1980) and Chang (1990).
} 
as the constraints faced by the maximizing player. The optimal contract is also found in section 3. The implications of this contract and the main results of the paper are presented in section 4 . Section 5 extends the model in a straightforward manner and discusses the main results. Section 6 concludes.

\section{The Model}

\subsection{Assumptions and Notation}

Before examining the basic model, let us first state the most relevant assumptions and present the variables and parameters used.

A.1. The agent is risk averse with a thrice differentiable von Neumann-Morgenstern utility function over final wealth such that $U^{\prime}(Y)>0, U^{\prime \prime}(Y)<0$ and $U^{\prime \prime \prime}(Y)>0$. The insurer is risk neutral.

A.2. There are $T+1$ states of nature: No accident, and $T$ possible losses if an accident occurs. An accident occurs with probability $\pi$. Conditional on an accident, the probability that loss $\lambda_{t}$ occurs is given by $\rho_{t}, \sum_{t=1}^{T} \rho_{t}=1$. The distribution $\left(\pi, \lambda_{t} \in\left\{\lambda_{1}, \lambda_{2}, \ldots, \lambda_{T}\right\}, \rho_{t} \in\left\{\rho_{1}, \rho_{2}, \ldots, \rho_{T}\right\}\right)$ is common knowledge. Without loss of generality, let $\lambda_{T}>\lambda_{T-1}>\ldots>\lambda_{1} \geq 0$. Suppose also that larger losses do not occur with greater frequency than smaller losses (i.e., $\left.\rho_{t} \geq \rho_{t+1}\right){ }^{6}$

A.3. The occurrence of an accident is common knowledge.

A.4. If an accident occurs, the agent and the insurer play a game of asymmetric information where the agent has private information on his loss. His possible actions are to report any loss $\lambda_{t} \in\left\{\lambda_{1}, \lambda_{2}, \ldots, \lambda_{T}\right\}$, while the possible actions for the insurer are to audit the claim $(A C)$ or not to audit $(N A)$.

A.5. The number of insurers is large, and the number of agents is even larger.

A.6. The insurance market is perfectly competitive in that the premium $(\alpha)$ is equal to the expected benefit plus expenses due to fraud.

A.7. Auditing a claim is costly to the insurer. This cost is fixed and equal to $c$.

A.8. Being caught defrauding is costly to the agent. Let $k$ be the fixed penalty imposed on the agent found guilty of fraud. ${ }^{7,8}$ This penalty is a deadweight cost to society in that it is paid by the

\footnotetext{
${ }^{6}$ Assuming that $\rho_{t} \geq \rho_{t+1}$ is not necessary; it just garantees that the probability of committing fraud will be smaller than one (see equation 2 ).

${ }^{7}$ In other words, the penalty imposed on those convicted of fraud is independent of the size of the lie, and set exogenously. On this point, I disagree with Mookherjee and Png (1989), who argue that a contract could include a provision for the penalty that is set at the same time as the other endogenous variables of the problem. In insurance, however, a contract does not specify the penalty imposed on those who commit fraud. Rather, the legal system deals with this crime in the same way as it deals with all other crimes.

${ }^{8}$ It is often the case, however, for the penalty imposed on agents found guilty of fraud to be dependent on both
} 
agent, but not collected by the insurer. This means that if the agent is caught committing fraud, then the insurer must still compensate him as if he had told the truth. Auditing is therefore not used to extract money from the agent. Detection is perfect if an audit happens.

Other variables/parameters used in the paper are $\alpha, \beta_{t}, \eta_{j t}, \nu_{t}$ and $A$. $\alpha$ represents the premium paid. $\beta_{t}$ represents the compensation received by the agent when he reports $\lambda_{t}$. Although the policyholder suffers loss $\lambda_{t} \in\left\{\lambda_{1}, \lambda_{2}, \ldots, \lambda_{T}\right\}$, the compensation he gets is given by $\beta_{t} \in\left\{\beta_{1}, \beta_{2}, \ldots, \beta_{T}\right\}$. $\eta_{j t}$ is the probability that an agent reports loss $\lambda_{t}$ given that his true loss is $\lambda_{j} . \nu_{t}$ is the probability that reported loss $\lambda_{t}$ is audited. Finally, $A$ is the agent's initial wealth.

In stage zero, an insurance contract is chosen. This contract stipulates a premium $(\alpha)$ and a coverage schedule $\left\{\beta_{1}, \beta_{2}, \ldots, \beta_{T}\right\}$. In the second stage of the game, Nature decides if an accident occurs or not. If an accident occurs the agent privately learns of the loss suffered. In stage 3 , he makes a report to the insurer. Only reports of $\lambda_{t} \in\left\{\lambda_{1}, \lambda_{2}, \ldots, \lambda_{T}\right\}$ are allowed and believable. Any other report is certain to be fraudulent since it cannot occur. The last move belongs to the insurer, who audits or does not audit the agent. Finally, the payoffs are paid and the game ends. The sequence of play is presented in Figure 1.

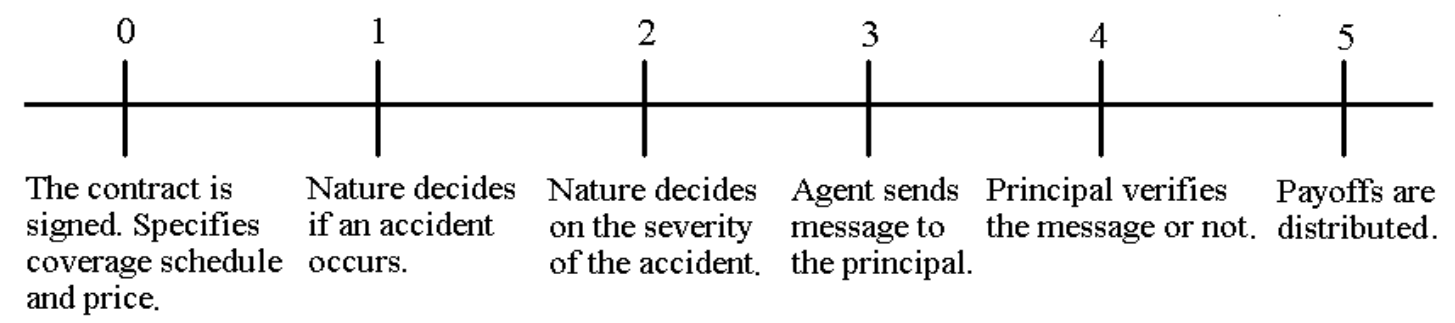

Figure 1: Sequence of play

\subsection{Choice Variables}

Without loss of generality, let the insurer be the maximizing player. In her design of contract, the insurer is able to choose $T+1$ variables: the coverage for $T$ types of loss, $\beta_{t}$, and the price of the contract $\alpha$. If no accident occurs, there is no possibility for the agent to exaggerate his claim, and the payoff to the agent and the insurer are $U(A-\alpha)$ and $\alpha$ respectively. If an accident does occur, however, the players will play what I call the claiming game.

the reported and the true state of world (or on the extent of the fraud). This will not matter in our setting as long as the penalty does not depend on any choice variable. Instead of having a fixed penalty for all agents who commit fraud $(k)$, we could let the penalty be dependent on both the true state of the world $\left(\lambda_{t}\right)$ and the reported state of the world $\left(\lambda_{j}>\lambda_{t}\right)$. In this case, we would only need to let $k=k\left(\lambda_{t}, \lambda_{j}\right)$ in the paper. None of the results would be altered since the penalty has no impact on the optimal contract, as we shall see in Section 3 , lemma 3. 
The players know that if an accident occurs, the agent may wish to exaggerate his claim (commit fraud). The insurer must then choose a payment schedule that anticipates rationally the behavior of each player in the claiming game. Her problem is then to maximize the agent's expected utility over final wealth

$$
\begin{aligned}
E U(Y)= & (1-\pi) U(A-\alpha)+\pi \sum_{t=1}^{T} \rho_{t} \eta_{t t} U\left(A-\alpha-\lambda_{t}+\beta_{t}\right) \\
& +\pi \sum_{t=1}^{T} \rho_{t} \sum_{j>t}^{T} \eta_{j t}\left(1-\nu_{j}\right) U\left(A-\alpha-\lambda_{t}+\beta_{j}\right) \\
& +\pi \sum_{t=1}^{T} \rho_{t} \sum_{j>t}^{T} \eta_{j t} \nu_{j} U\left(A-\alpha-\lambda_{t}+\beta_{t}-k\right)
\end{aligned}
$$

$U(A-\alpha)$ is the utility the agent receives if no accident occurs. Since the occurrence of an accident is common knowledge and the agent cannot cause an accident on purpose, the claiming game is not played. With probability $\pi$ an accident occurs, and the severity of the accident is revealed to the agent. An accident of severity $\lambda_{t}$ occurs with conditional probability $\rho_{t}$. In this case, the agent tells the truth with probability $\eta_{t t}$; in which case he receives utility $U\left(A-\alpha-\lambda_{t}+\beta_{t}\right)$. With probability $\eta_{j t}$ the agent who suffered loss $\lambda_{t}$ reports to the insurer that he suffered loss $\lambda_{j}$, with $\lambda_{j}>\lambda_{t} \cdot{ }^{9}$ If the agent reports loss $\lambda_{j}$, he is audited with probability $\nu_{j}$. Since audits are perfect, an agent who commits fraud and who is audited is always caught. In this instance, his utility is $U\left(A-\alpha-\lambda_{t}+\beta_{t}-k\right)$. If he is not audited, then he receives utility $U\left(A-\alpha-\lambda_{t}+\beta_{j}\right)$. This maximization problem is subject to certain constraints, as presented below.

\subsection{The Constraints}

There are three types of constraints in this model: Perfect Bayesian Nash Equilibrium (PBNE), Zero-profit (ZP) and Participation (PC). The PBNE constraints give us the equilibrium behavior of the players in the claiming game. These constraints replace the incentive compatibility constraint found in traditional models with commitment. The ZP constraint says that the insurer, in expectation, is making no profits. Finally the PC constraint states that the agent is better off participating in this economy than in autarchy. Let us start with the PBNE constraints.

\subsubsection{Nash equilibrium constraints}

In the claiming game between the policyholder and the insurer, there is only one possible type of PBNE in mixed strategy. This PBNE is such that only one type of agent ever plays a mixed

\footnotetext{
${ }^{9}$ It does not make sense to under-report a loss in this model, since the game is only played once, and there is no experience rating. Thus the agent has no strategic incentive to under-report his loss in order to potentially reduce his future premium.
} 
strategy that involves truth telling. By definition, the PBNE of this game is

Definition 1 A PBNE is defined in this game as

$$
\begin{aligned}
P B N E & =\left(\begin{array}{c}
\text { Agent's strategy if Nature chose } \lambda=\lambda_{t} \\
\text { insurer's strategy if the Agent reported } \lambda=\lambda_{t} \\
\text { Beliefs for the insurer in the information set resulting from } \left.\lambda=\lambda_{t}\right)
\end{array}\right) \\
& =\left(\theta_{1}, \ldots, \theta_{T} ; \delta_{1}, \ldots, \delta_{T} ; \gamma_{1}, \ldots, \gamma_{T}\right)
\end{aligned}
$$

We will denote this equilibrium as

$$
\begin{aligned}
\theta & : \quad\left\{\lambda_{1}, \ldots, \lambda_{T}\right\} \rightarrow \Delta\left\{\lambda_{1}, \ldots, \lambda_{T}\right\} \\
\delta & : \quad\left\{\lambda_{1}, \ldots, \lambda_{T}\right\} \rightarrow \Delta\{A C, N A\} \\
\gamma: & \left\{\lambda_{1}, \ldots, \lambda_{T}\right\} \rightarrow[0,1]
\end{aligned}
$$

where the notation $\theta:\left\{\lambda_{1}, \ldots, \lambda_{T}\right\} \rightarrow \Delta\left\{\lambda_{1}, \ldots, \lambda_{T}\right\}$ means that $\theta$ is a function of the observed signal $\left\{\lambda_{1}, \ldots, \lambda_{T}\right\}$ to a probability distribution $\Delta$ of messages $\left\{\lambda_{1}, \ldots, \lambda_{T}\right\}$.

Before deriving the PBNE, let us simplify the analysis by using the following lemma.

Lemma 1 A fixed payment will be paid for all claimed losses that are never audited. Furthermore the no-auditing region is always at the lower end of the distribution of losses.

Proof: See Townsend (1979), Gale and Hellwig (1985), or Bond and Crocker (1997). ${ }^{10} \bullet$

Lemma 1 tells us that for all reported losses less than or equal to some cutoff point $\lambda_{t^{*}}$, the insurer never audits the agent's report, and the agent receives a constant payment independent of his real loss. The intuition behind this lemma is as follows. Suppose that some subset of claims is not audited, and that the payments associated with the different claims are not equal. An agent will then always claim for the loss associated with the highest payment, since he has no chance of getting caught. Therefore, all claims that are not audited must receive the same compensation.

\footnotetext{
${ }^{10}$ It is intuitively obvious that a fixed payment must be paid for all states that are never audited. Consider the opposite, that one state $\omega$ in the set of non-audited states $\Omega$ pays $\beta_{\omega}>\beta_{w}$ for all $w \in \Omega \backslash \omega$. Since no state in $\Omega$ is ever audited, every rational agent will report the state where he has the most to gain, that is state $\omega$. This means that any agent who suffered a loss $\lambda_{w}$, with $w \in \Omega$, will receive payment $\beta_{\omega}$ since state $\omega$ is never audited.

As for the second part of the proof, although our setup is slightly different for Townsend's and Gale and Hellwig's, the intuition is the same. In states where losses are smaller (or gains are greater in Townsend and in Gale and Hellwig), the principal should not audit. In a debt contract context, the state where gains are greater (losses are smaller) corresponds to states where agents can repay their debt; in an insurance context, the state where losses are smaller (gains are greater) corresponds to states where agents can assume the loss without being indemnified.
} 
The second part of the lemma is also intuitive. Suppose the no-auditing region is not at the lower end of the distribution of losses. Since benefits do not decrease with loss size, an agent has nothing to lose by reporting a higher loss that is never audited. This means that agents with lower losses will always claim for a higher loss if that higher loss is never audited. Therefore, the no-auditing region must be at the lower end of the loss distribution.

Using lemma 1, it is then possible to derive a PBNE of the claiming game. It is clear given the $T$-point distribution of losses, that there is a plethora of equilibriums. Not all possible equilibriums of this game are presented. Instead I shall concentrate on a subset of equilibriums that share the same properties. One property is that a fixed payment shall be paid for all claimed losses that are never audited, and that the losses that are never audites lie at the lower end of the distribution of losses. In other words, I will suppose that lemma 1 holds. Furthermore, I will assume for those losses that are audited with some probability that larger losses are compensated more than smaller losses, but that the rate of increase is smaller than one (i.e., $\frac{\partial \beta_{t}}{\partial \lambda_{t}} \in(0,1)$ ). I will posit the conjecture that an equilibrium of this type is played in the claiming game. It is quite possible that other types of equilibriums exist in this game, but I will not examine them. These conjectured equilibriums are presented in the following lemma.

Lemma 2 Assume that $\frac{\partial \beta_{t}}{\partial \lambda_{t}} \in(0,1) ;{ }^{11}$ there is then a set of PBNE of this game such that: 1-Only one agent plays a mixed strategy which involves telling the truth (say agent $\lambda_{t^{*}}$ ); 2-Agent $t^{*}$ is indifferent between telling the truth and reporting anything above;

3-All agents with loss $\lambda_{t}>\lambda_{t^{*}}$ tell the truth;

4-All agents with loss $\lambda_{t}<\lambda_{t^{*}}$ tell the truth.

With $\eta_{t t^{\prime}}$ representing the probability that an agent who suffered real loss $\lambda_{t}$ reports loss $\lambda_{t^{\prime}}$, we obtain that for all $\lambda_{t} \neq \lambda_{t^{*}}, \eta_{t t}=1$. As for loss $\lambda_{t^{*}}$, the probability that loss $\lambda_{t^{\prime}}>\lambda_{t^{*}}$ is reported is given by

$$
\eta_{t^{*} t^{\prime}}=\left(\frac{c}{\beta_{t^{\prime}}-\beta_{t^{*}}-c}\right) \frac{\rho_{t^{\prime}}}{\rho_{t^{*}}}
$$

Meanwhile $\nu_{t}$, which represents the probability that a loss of size $\lambda_{t}$ is audited, is given by

$$
\nu_{t}=\frac{U\left(A-\alpha-\lambda_{t^{*}}+\beta_{t}\right)-U\left(A-\alpha-\lambda_{t^{*}}+\beta_{t^{*}}\right)}{U\left(A-\alpha-\lambda_{t^{*}}+\beta_{t}\right)-U\left(A-\alpha-\lambda_{t^{*}}+\beta_{t^{*}}-k\right)}
$$

for all $t>t^{*}$, while $\nu_{t}=0$ for all $1 \leq t \leq t^{*}$. The beliefs supporting this equilibrium are displayed in Table 1 in the appendix.

\footnotetext{
${ }^{11}$ Assuming that $\frac{\partial \beta}{\partial \lambda}>0$ makes intuitive sense: an insurance contract should idemnify agents more the greater their loss (i.e., $\beta_{t}<\beta_{t+1}$ ). The fact that we would want to bound the rate of increase is more of a technical condition for the equilibrium to hold. This assumption is that same as saying that $\beta_{t}-\lambda_{t}>\beta_{t+1}-\lambda_{t+1}$. Proposition 2 shows that this condition does indeed hold for the optimal contract.
} 


\section{Proof: See Appendix. All remaining proofs are in the appendix.}

This lemma gives us possible reporting and auditing strategies in equilibrium. The probability of auditing a reported loss of size $\lambda_{t}>\lambda_{t^{*}}$ is such that the agent who suffered a loss equal to $\lambda_{t^{*}}$ is indifferent about telling the truth or reporting any loss above. For losses $\lambda_{t}>\lambda_{t^{*}}$ the agent is better off telling the truth. Finally, for all losses $\lambda_{t}<\lambda_{t^{*}}$, the agent reports loss $\lambda_{t^{*}}$ because all losses less than or equal to $\lambda_{t^{*}}$ are never audited. This equilibrium may not be unique. It only displays characteristics which are encountered in easier problems.

For example, this conjectured type of equilibrium displays the same properties as the unique equilibrium in a 2-point distribution (see Picard, 1996, and Boyer, 2000). If we look at the insurer's auditing strategy in this type of equilibrium, it is clear that there is no point in auditing at the lower end of the distribution since the compensation is fixed. If we look at the upper end of the distribution, we see that the insurer audits with some probability. This probability increases as the payment increases $\left(\frac{\partial \nu}{\partial \beta_{t}}>0\right)$, just as in Mookherjee and Png (1989) and in Graetz, Reinganum and Wilde (1986). This also makes intuitive sense: If the insurer has more to lose by paying larger indemnity payments, then she will take extra precautions to make sure that such indemnity payments are made to the right person for the right reason.

In the Townsend (1979) model, lower losses are never audited, as in the present model. This means that a flat payment must be paid. As losses increase, the indemnity payment never decreases. In fact, the indemnity payment must increase. The indemnity increase is smaller than the loss increase, which means, as in here, that $\frac{\partial \beta_{t}}{\partial \lambda_{t}} \in(0,1){ }^{12}$

This equilibrium predicts that only one type of agent will ever commit fraud in this economy (the agent who suffered loss $\lambda_{t^{*}}$ ). This means that fraud is committed in this economy with probability $\rho_{t^{*}}$ at most. This does not necessarily mean that the probability of observing fraud goes to zero as the number of possible states goes to infinity (unless of course losses are continuous). For example, we could have a very large number of states with probability arbitrarily close to zero, except for loss $\lambda_{t^{*}}$ that occurs with probability $\rho_{t^{*}}$ much larger than zero.

This equilibrium rests on the assumptions that $\frac{\partial \beta_{t}}{\partial \lambda_{t}} \in(0,1)$ and on lemma 1 . In other words, the only assumption we made regarding the shape of the contract is that: 1- indemnity payment does not decrease as the reported loss increases; 2- for all states that are not audited by the principal the indemnity payment is constant; and 3- the no-auditing region is at the lower end of the distribution of losses. I do not take into account the maximization over the indemnity payment yet, although some conditions on the shape of the contract are made.

\footnotetext{
${ }^{12}$ The empirical findings of Crocker and Tennyson (1999) support the view that indemnity payments increase slower than losses. I discuss this later in the paper.
} 


\subsubsection{Zero-profit constraint}

The next constraint presented is the zero-profit constraint for the insurer. The premium paid by the policyholder must include the fact that some fraudulent claims go undetected, and that auditing a claim is costly whether it is fraudulent or not. The price of the policy is then given by the following implicit function.

$$
\alpha=\pi \sum_{t=1}^{T} \rho_{t} \eta_{t t} \beta_{t}+\pi \sum_{t=1}^{T} \rho_{t} \sum_{j>t}^{T} \eta_{j t}\left[\left(1-\nu_{j}\right) \beta_{j}+\nu_{j} \beta_{t}\right]+\pi c\left(\sum_{t=1}^{T} \rho_{t} \eta_{t t} \nu_{t}+\sum_{t=1}^{T} \rho_{t} \sum_{j>t}^{T} \eta_{j t} \nu_{j}\right)
$$

The first term represents the principal's payment if the agent tells the truth, where $\eta_{t t}$ is the probability that the agent tells the truth if his loss is equal to $\lambda_{t}$. This first term does not depend on whether the principal audits the claim, by assumption; the amount paid is then $\beta_{t}$. The second term represents the principal's expected payment, given that the agent exaggerates his claim; an agent who suffered loss $\lambda_{t}$ with probability $\rho_{t}$ reports loss $\lambda_{j}$ with probability $\eta_{j t}$. When an agent report loss $\lambda_{j}$, he is audited with probability $\nu_{j}$. Since audits are perfect, the principal need only pay $\beta_{t}$, by assumption. With probability $1-\nu_{j}$ the agent is not audited, which means that the principal must pay $\beta_{j}$. The third term represents the expected cost of the auditing strategy. All audits cost the same $(c)$ whether a truthful report is filed (with probability $\sum_{t=1}^{T} \rho_{t} \eta_{t t}$ ) or not (with probability $\left.\sum_{t=1}^{T} \rho_{t} \sum_{j>t}^{T} \eta_{j t}\right)$.

\subsubsection{Participation constraint}

The last condition to consider is the participation constraint of the agent:

$$
E U^{*}(Y) \geq(1-\pi) U(A)+\pi \sum_{t=1}^{T} \rho_{t} U\left(A-\lambda_{t}\right)
$$

where $E U^{*}(Y)$ is the agent's expected utility at equilibrium when he purchased the contract. This constraint states that the agent must be better off in this economy than in autarchy.

\section{Contract}

The problem for the insurer is to choose a coverage schedule and a premium that maximizes the agent's expected von Neumann-Morgenstern utility function over final wealth. Mathematically,

$$
\begin{aligned}
\max _{\beta_{1}, \beta_{2}, \ldots, \beta_{T}, \alpha} E U(Y)= & (1-\pi) U(A-\alpha)+\pi \sum_{t=1}^{T} \rho_{t} \eta_{t t} U\left(A-\alpha-\lambda_{t}+\beta_{t}\right) \\
& +\pi \sum_{t=1}^{T} \rho_{t} \sum_{j>t}^{T} \eta_{j t}\left(1-\nu_{j}\right) U\left(A-\alpha-\lambda_{t}+\beta_{j}\right)
\end{aligned}
$$




$$
+\pi \sum_{t=1}^{T} \rho_{t} \sum_{j>t}^{T} \eta_{j t} \nu_{j} U\left(A-\alpha-\lambda_{t}+\beta_{t}-k\right)
$$

subject to the PBNE strategy constraint of the agent

$$
\begin{array}{cl}
\eta_{t t}=1 & \text { if } \lambda_{t}<\lambda_{t^{*}} \\
\eta_{t^{*} t^{\prime}}=\left(\frac{c}{\beta_{t^{\prime}}-\beta_{t^{*}}-c}\right) \frac{\rho_{t^{\prime}}}{\rho_{t^{*}}} & \text { if } \lambda_{t}=\lambda_{t^{*}} \\
\eta_{t t}=1 & \text { if } \lambda_{t}>\lambda_{t^{*}}
\end{array}
$$

the PBNE strategy constraint of the insurer

$$
\begin{aligned}
& \nu_{t}=0 \quad \text { if } 1 \leq t \leq t^{*}
\end{aligned}
$$

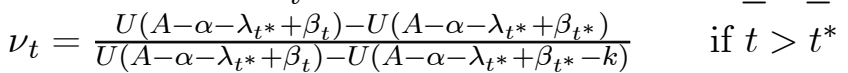

the zero profit constraint

$$
\alpha=\pi \sum_{t=1}^{T} \rho_{t} \eta_{t t} \beta_{t}+\pi \sum_{t=1}^{T} \rho_{t} \sum_{j>t}^{T} \eta_{j t}\left[\left(1-\nu_{j}\right) \beta_{j}+\nu_{j} \beta_{t}\right]+\pi c\left(\sum_{t=1}^{T} \rho_{t} \eta_{t t} \nu_{t}+\sum_{t=1}^{T} \rho_{t} \sum_{j>t}^{T} \eta_{j t} \nu_{j}\right)
$$

and the participation constraint

$$
E U^{*}(Y) \geq(1-\pi) U(A)+\pi \sum_{t=1}^{T} \rho_{t} U\left(A-\lambda_{t}\right)
$$

This maximization problem is quite complicated. There are $T+1$ decision variables and $3 T-$ $t^{*}+2$ constraints. Fortunately, by substituting (7), (8) and (9) into (6) the problem can be simplified as shown in the following lemma.

Lemma 3 The maximization problem may be simplified to

$$
\begin{aligned}
\max _{\beta_{t^{*}}, \beta_{t^{*}+1}, \ldots, \beta_{T}} E U(.)= & (1-\pi) U\left(A-\pi\left[\beta_{t^{*}}+\sum_{t=t^{*}+1}^{T} \rho_{t} \frac{\left(\beta_{t}-\beta_{t^{*}}\right)^{2}}{\left(\beta_{t}-\beta_{t^{*}}-c\right)}\right]\right) \\
& +\sum_{t=1}^{t^{*}} \pi \rho_{t} U\left(A-\pi\left[\beta_{t^{*}}+\sum_{t=t^{*}+1}^{T} \rho_{t} \frac{\left(\beta_{t}-\beta_{t^{*}}\right)^{2}}{\left(\beta_{t}-\beta_{t^{*}}-c\right)}\right]-\lambda_{t}+\beta_{t^{*}}\right) \\
& +\sum_{t=t^{*}+1}^{T} \pi \rho_{t} U\left(A-\pi\left[\beta_{t^{*}}+\sum_{t=t^{*}+1}^{T} \rho_{t} \frac{\left(\beta_{t}-\beta_{t^{*}}\right)^{2}}{\left(\beta_{t}-\beta_{t^{*}}-c\right)}\right]-\lambda_{t}+\beta_{t}\right)
\end{aligned}
$$

subject to

$$
E U^{*}(Y) \geq(1-\pi) U(A)+\pi \sum_{t=1}^{T} \rho_{t} U\left(A-\lambda_{t}\right)
$$


Suppose the participation constraint does not bind - I discuss why this is so in section 4 . The problem then becomes a standard unconstrained problem with $T-t^{*}+1$ variables. It is interesting to note that the penalty $(k)$ is nowhere to be found in (11). This means that the optimal contract will be independent of the penalty the agent may pay if he is caught cheating his insurer. The reason this occurs is precisely because of the impossibility for the insurer to commit to an auditing strategy. Since the decision to audit comes last in the sequence of play, the insurer will adjust her auditing strategy to reflect the penalty. It is clear from (8) that the greater the penalty, the lower the probability of audit. The relationship between $\nu_{t}$, for $t>t^{*}$, and $k$ is such that, whatever the penalty may be, the principal sets her auditing strategy in such a way as to make the agent indifferent as to whether he cheats or does not cheat. This implies that in the end, the penalty is irrelevant since the auditing strategy is chosen to ensure that this is so. This is true even if the size of the penalty depends on the reported state $\left(\lambda_{j}\right)$ and/or the true state of the world $\left(\lambda_{t}\right)$; in other words, if the penalty can be written as $k=k\left(\lambda_{t}, \lambda_{j}\right)$.

The necessary conditions for an optimum are ${ }^{13}$

$$
\frac{\pi \sum_{t=1}^{t^{*}} \rho_{t} U^{\prime}\left(A-\alpha-\lambda_{t}+\beta_{t^{*}}\right)}{E U^{\prime}(.)}=\pi-\sum_{t=t^{*}+1}^{T} \frac{\partial \alpha}{\partial \beta_{t}}
$$

and

$$
\frac{\pi \rho_{j} U^{\prime}\left(A-\alpha-\lambda_{j}+\beta_{j}\right)}{E U^{\prime}(.)}=\frac{\partial \alpha}{\partial \beta_{j}} \quad \forall j \geq t^{*}+1
$$

where, for simplicity, the following changes of variables have been made.

$$
E U^{\prime}(.)=(1-\pi) U^{\prime}(A-\alpha)+\sum_{t=1}^{t^{*}} \pi \rho_{t} U^{\prime}\left(A-\alpha-\lambda_{t}+\beta_{t^{*}}\right)+\sum_{t=t^{*}+1}^{T} \pi \rho_{t} U^{\prime}\left(A-\alpha-\lambda_{t}+\beta_{t}\right)
$$

${ }^{13}$ The first order conditions are

$$
\begin{aligned}
\frac{\partial}{\partial \beta_{t^{*}}}= & 0=-(1-\pi) U^{\prime}(A-\alpha) \frac{\partial \alpha}{\partial \beta_{t^{*}}}-\sum_{t=t^{*}+1}^{T} \pi \rho_{t} U\left(A-\alpha-\lambda_{t}+\beta_{t}\right) \frac{\partial \alpha}{\partial \beta_{t^{*}}} \\
& +\sum_{t=1}^{t^{*}} \pi \rho_{t} U^{\prime}\left(A-\alpha-\lambda_{t}+\beta_{t^{*}}\right)\left(1-\frac{\partial \alpha}{\partial \beta_{t^{*}}}\right)
\end{aligned}
$$

and, $\forall j \geq t^{*}+1$

$$
\begin{aligned}
\frac{\partial}{\partial \beta_{j}}= & 0=-(1-\pi) U^{\prime}(A-\alpha) \frac{\partial \alpha}{\partial \beta_{j}}-\sum_{t=1}^{t^{*}} \pi \rho_{t} U^{\prime}\left(A-\alpha-\lambda_{t}+\beta_{t^{*}}\right) \frac{\partial \alpha}{\partial \beta_{j}} \\
& +\pi \rho_{j} U^{\prime}\left(A-\alpha-\lambda_{j}+\beta_{j}\right)-\sum_{t=t^{*}+1}^{T} \pi \rho_{t} U\left(A-\alpha-\lambda_{t}+\beta_{t}\right) \frac{\partial \alpha}{\partial \beta_{j}}
\end{aligned}
$$


and

$$
\begin{gathered}
\frac{\partial \alpha}{\partial \beta_{j}}=\pi \rho_{j}\left[1-\left(\frac{c}{\beta_{t}-\beta_{t^{*}}-c}\right)^{2}\right]=\pi \rho_{j} \frac{\left(\beta_{j}-\beta_{t^{*}}\right)\left(\beta_{j}-\beta_{t^{*}}-2 c\right)}{\left(\beta_{j}-\beta_{t^{*}}-c\right)^{2}} \forall j \geq t^{*}+1 \\
\frac{\partial \alpha}{\partial \beta_{t^{*}}}=\pi \sum_{t=1}^{t^{*}} \rho_{t}+\pi \sum_{t=t^{*}+1}^{T} \rho_{t}\left(\frac{c}{\beta_{t}-\beta_{t^{*}}-c}\right)^{2}=\pi-\sum_{j=t^{*}+1}^{T} \frac{\partial \alpha}{\partial \beta_{j}}
\end{gathered}
$$

What do these equations tell us? The denominator on the left-hand side of each equation can be seen as the expected marginal utility of wealth given the coverage schedule chosen. These necessary conditions do not tell us much more, however. Fortunately, the most interesting implications will come to light in the coming section.

\section{Results and Implications}

Equations (13) and (14) give us the necessary conditions for an optimal contract. In this section I present the implications and the predictions of such a contract. The first implication is that the agent does not choose a contract where he gets the same wealth ex post in every state.

Proposition 1 There exist a $\lambda_{j}$ such that $\beta_{j} \neq \lambda_{j}$.

When the agent buys a contract where he has more wealth in one state than in another, this means he does not receive the same marginal utility in every state. Stated differently, the contract does not provide perfect income smoothing. Proposition 1 does not tell us, however, in which state the agent has relatively more wealth. Also, it does not tell us whether the agent is under-insured and/or over-insured, and in what state either occurs. This result is in accordance with other results in the literature. When information is not symmetric, perfect income smoothing does not occur. This result has nothing to do with whether the insurer is able to commit or not. For example, the contracts of Townsend (1979) and Mookherjee and Png (1989) do not display perfect income smoothing even though the insurer is able to commit to an auditing strategy.

Proposition 2 The payment schedule has a slope of less than one for losses strictly greater than $\lambda_{t^{*}}$.

Proposition 2 tells us that as the real loss increases, the difference between the benefit paid and the real loss decreases. What it does not say is whether the agent is over- or under-compensated, and when. This means that either the amount by which a loss is over-paid decreases, or the amount 
by which it is under-paid increases. The reason why the slope is less than one is that the insurer places more weight on the auditing part of her strategy as the loss increases (i.e., $\frac{\partial \nu}{\partial \beta_{t}}>0$ for all $t>t^{*}$ ). Therefore, she has to over-pay large losses less (under-pay large losses more) to maintain agent indifference between cheating and not cheating.

Using propositions 1 and 2, the following theorem shows that the agent chooses a contract that provides full insurance across the two accident states. This is not to say that the agent receives a payment equal to his loss in every state, which never happens, as proposition 1 showed. Instead, full insurance across the two accident states simply means that the agent obtains the same expected marginal utility in the accident state as in the no-accident state.

Theorem 1 The agent's expected marginal utility is equal in the accident state and in the noaccident state.

The difference between receiving the same expected marginal utility in the accident state as in the no accident state, and receiving the same marginal utility in every state is the difference between full insurance and perfect income smoothing. Theorem 1 shows that the contract allows the policyholder to receive full insurance, although it does not perfectly smooth his income.

Even if the agent over-reports his loss with some probability, he chooses a contract that provides him with the same expected utility in the accident and no-accident states. The only welfare cost to agents of ex post moral hazard comes from a general lowering of their utility possibility frontier. If the expected utilities are the same, will the expected wealth also be the same? The answer depends on the third derivative of the utility function. If $U^{\prime \prime \prime}()>$.0 , then the marginal utility function is convex. This means that the average of the marginal utilities of wealth is greater than the marginal utility of the average wealth. Thus, the expected wealth in the accident state must be greater than in the no-accident state. The reasoning is reversed for $U^{\prime \prime \prime}()<$.0 . Thus, at least one loss is under-compensated. The question becomes which one.

The following corollary answers that question. Corollary 1 also provides an answer to where the compensation associated with losses greater than $\lambda_{t^{*}}$ is located vis-à-vis the loss itself.

Corollary $1 \beta_{t}>\lambda_{t} \forall t>t^{*}$, whereas $\beta_{t^{*}}<\lambda_{t^{*}}$.

In other words, losses greater than the cutoff point are over-compensated, and a fixed payment of $\beta_{t^{*}}<\lambda_{t^{*}}$ is made to the agents with a loss less than or equal to $\lambda_{t^{*}}$. Corollary 1 implies that policyholders receive greater utility in the states where they suffer a loss greater than $\lambda_{t^{*}}$ than in the no-accident state. It also means that they receive smaller expected utility in the states where 
they suffer a loss equal to $\lambda_{t^{*}}$ than in the no-accident state. We can see what is happening more clearly by looking at Figure 2, where the optimal contract is displayed.

Figure 2: Optimal contract

The real loss suffered by the policyholder is on the horizontal axis, while the payment received in the event of an accident is on the vertical axis. From lemma 1, the coverage chosen by the policyholder for losses less than or equal to $\lambda_{t^{*}}$ is a constant, $\beta_{t^{*}}$; with $\beta_{t^{*}}<\lambda_{t^{*}}$ from corollary 1 . This means that for some ranges of losses (less than $\lambda_{t^{*}}$ and relatively close to $\lambda_{t^{*}}$ ) the policyholder receives a payment that is less than his loss. Unfortunately it is impossible to say whether all losses of less than $\lambda_{t^{*}}$ will be under-paid. What can be said, however, is that if there exists a $\lambda_{t}$ such that $\lambda_{t}=\beta_{t^{*}}$, then for all losses $\lambda<\lambda_{t}$, the policyholder will be over-compensated, while for all losses $\lambda \in\left(\lambda_{t}, \lambda_{t^{*}}\right]$, the policyholder will be under-compensated.

Finally, for all losses greater than $\lambda_{t^{*}}$ the agent receives a payment that is greater than his loss. Furthermore, the difference between the payment received and the real loss decreases as the real loss increases (proposition 2). This is represented by the payment schedule for losses greater than $\lambda_{t^{*}}$, which has a slope less than one. The over-payment of a loss greater than $\lambda_{t^{*}}$ is true even for very high losses. In the limit, for the highest loss the difference between the payment and the loss can be arbitrarily close to zero. 
The main reason why an agent is over-compensated for higher losses is that his probability of filing a fraudulent claim decreases when the difference between the coverage in the reported loss state and the real loss state increases: i.e., $\frac{\partial \eta_{t t^{*}}}{\partial\left(\beta_{t}-\beta_{t^{*}}\right)}<0$. The reduction in the probability of fraud is a result of the insurer's implicit partial commitment to more frequent audits; since she has more to lose by not auditing $\left(\beta_{t}-\beta_{t^{*}}>\lambda_{t}-\lambda_{t^{*}}\right)$, the agent should expect her to audit more, and therefore he should not be so inclined to commit fraud. In other words, the agent needs to increase the weight he puts on telling the truth in his optimal reporting strategy.

Another reason why over-compensating higher losses is optimal is that it reduces deadweight losses in the economy. In the model, there are two types of deadweight losses: the cost of auditing $(c)$ and the penalty for getting caught $(k)$. Fraudulent claims that are not detected are not deadweight losses; they are only transfers from the insurer to the agent. It is clear that agents pay the deadweight penalty less often when there are fewer fraud attempts. Also, the resources devoted to auditing may diminish. This occurs because the total number of reported losses greater than $\lambda_{t^{*}}$ is reduced, which means that the total number of audits may be reduced.

The last element of the contract to be discussed is the fact that the participation constraint does not bind. Let us suppose it does. This gives the same expected utility to the agent as choosing a contract where the payment schedule is such that $\beta_{t}=0 \forall t \in\{1,2, \ldots, T\}$. If we let $\beta_{t}=0 \forall t$, it is clear that $\alpha=0$. Thus, the agent's expected utility is

$$
E U(.)=(1-\pi) U(A)+\sum_{t=1}^{T} \pi \rho_{t} U\left(A-\lambda_{t}\right)
$$

It is easy to show that this is not optimal. Using (13) and (14), we get

$$
\frac{\pi \sum_{t=1}^{t^{*}} \rho_{t} U^{\prime}\left(A-\lambda_{t}\right)}{(1-\pi) U^{\prime}(A)+\sum_{t=1}^{T} \pi \rho_{t} U^{\prime}\left(A-\lambda_{t}\right)}=\pi-\sum_{t=t^{*}+1}^{T} \frac{\partial \alpha}{\partial \beta_{t}}
$$

and

$$
\frac{\pi \rho_{j} U^{\prime}\left(A-\lambda_{j}\right)}{(1-\pi) U^{\prime}(A)+\sum_{t=1}^{T} \pi \rho_{t} U^{\prime}\left(A-\lambda_{t}\right)}=\frac{\partial \alpha}{\partial \beta_{j}} \quad \forall j \geq t^{*}+1
$$

Substituting the second equality in the first yields

$$
\frac{\pi \sum_{t=1}^{t^{*}} \rho_{t} U^{\prime}\left(A-\lambda_{t}\right)}{(1-\pi) U^{\prime}(A)+\sum_{t=1}^{T} \pi \rho_{t} U^{\prime}\left(A-\lambda_{t}\right)}=\pi-\sum_{t=t^{*}+1}^{T} \frac{\pi \rho_{j} U^{\prime}\left(A-\lambda_{j}\right)}{(1-\pi) U^{\prime}(A)+\sum_{t=1}^{T} \pi \rho_{t} U^{\prime}\left(A-\lambda_{t}\right)}
$$

Equation (21) holds if and only if

$$
\sum_{t=1}^{T} \rho_{t} U^{\prime}\left(A-\lambda_{t}\right)=U^{\prime}(A)
$$

which is not possible. Therefore $\beta_{t}=0 \forall t \in\{1,2, \ldots, T\}$ cannot be optimal. 
The next section of the paper compares my contract with other contracts derived in the literature and discusses the findings. Although a large number of models and insurance contracts have been developed over the years, I will limit my comparison to the two models which most closely resemble the one described here.

\section{$5 \quad$ Extension and Discussion}

\subsection{Extension}

A major concern regarding this contract is that there does not seem to be any empirical evidence to support the view that high losses should be over-compensated. Quite the contrary. Crocker and Tennyson (1997) find that higher losses are typically underpaid, and that losses are underpaid even more as they increase in size. This second result supports my contract's specification that the payoff schedule of higher losses has a slope of less than one (see proposition 2). The question is then: how can the first empirical result of Crocker and Tennyson - higher losses underpaid be reconciled with my contract's provisions. One possible way, suggested by Boyer (1997), is to include expenses in the form of a proportional premium loading factor.

In my model, I assumed there were no expenses other than those incurred to pay for audits. Other expenses such as underwriting costs, marketing costs and commissions were assumed away. If we were to represent these expenses by a proportional load $(1+m)$ on the premium, then the optimal benefits received by the policyholder would be reduced: the higher the load, the lower the benefits. Eventually, the load may be so large that no over-payment of higher losses would ever be chosen, just as Crocker and Tennyson (1997) contend.

The Crocker and Tennyson paper is basically a test of the costly state verification contract versus the costly state falsification contract (CSF). The CSF approach, pioneered by Lacker and Weinberg (1989) and used by Crocker and Morgan (1998), is based on the premise that agents can incur a falsification cost in order to hide their actual loss from the insurer forever. This approach means that the insurer is never capable of detecting whether the agent has committed fraud or not, since the actual state of the world is impossible to detect. The optimal contract in a CSF world is such that lower losses are over-compensated, while higher losses are over-compensated.

A CSF contract has the property that the slope of the contract line is less than one, just as in the model presented in this paper. The difference is that Crocker and Morgan's contract cuts the forty-five degree line, whereas my contract does not. This situation may be resolved by including 
a proportional premium loading factor. The maximization problem would then become

$$
\begin{aligned}
\max _{\beta_{t^{*}, \beta_{t^{*}+1}, \ldots, \beta_{T}, \alpha} V=} \quad(1-\pi) U(A-(1+m) \alpha)+\sum_{t=1}^{t^{*}} \pi \rho_{t} U\left(A-(1+m) \alpha-\lambda_{t}+\beta_{t^{*}}\right) \\
+\sum_{t=t^{*}+1}^{T} \pi \rho_{t} U\left(A-(1+m) \alpha-\lambda_{t}+\beta_{t}\right)
\end{aligned}
$$

subject to

$$
\alpha=\pi\left[\beta_{t^{*}}+\sum_{t=t^{*}+1}^{T} \rho_{t} \frac{\left(\beta_{t}-\beta_{t^{*}}\right)^{2}}{\left(\beta_{t}-\beta_{t^{*}}-c\right)}\right]
$$

It is then straightforward to show that the loading factor $(1+m)$ can be chosen at a high enough level for the CSF contract to be obtained; that is, larger losses are under-compensated while smaller losses are over-compensated. This is proven as the following proposition.

Proposition 3 There exists a loading factor $(1+m)>1$ such that the optimal contract crosses the forty-five degree line at some $t>t^{*}$.

This means that the form of the contract is basically the same whether we use a CSF framework or a CSV framework where the insurer cannot commit to an auditing strategy, and where a proportional premium loading factor exists. The advantage of my model is that it accounts for the observance of agents who are caught committing fraud. In the CSF literature, agents cannot be caught committing fraud since they can hide the true state of the world from the insurer forever.

There is still the problem of over-compensation of some losses. This is not hard to resolve. We can set the loading factor high enough so that no over-compensation is ever obtained.

Corollary 2 There exists an $m$ such that $\beta_{t^{*}+1} \leq \lambda_{t^{*}+1}$.

Corollary 2 means that it is possible to find a loading factor high enough to ensure that no overcompensation ever occurs. To see why that is, we need only recall that the slope of the contract line for losses greater than $\lambda_{t^{*}}$ is less than 1. If the lower end of the contract line is below the 45-degree line, then all the line must also be below it too. Finally, corollary 3 shows the impact of the loading factor on the flat payment.

Corollary 3 As $m$ increases, $\beta_{t^{*}}$ decreases.

Corollary 3 stipulates that the flat payment decreases as the loss increases. Obviously, this reduction occurs in a parallel fashion since the payment is flat. These last three results are intuitive. 
As the deadweight cost of buying insurance (loading) increases, agents want to buy less of it. Consequently, the benefit schedule must decrease. This is exactly what is happening. This optimal contract is displayed in Figure 3. The contract has the familiar feature of a deductible, a lump-sum payment and coinsurance.

Figure 3: Optimal contract with high proportional loading factor

For all losses less than $\lambda_{t^{*}}$, the fixed benefit paid by the insurer can be set arbitrarily close to $\beta_{t^{*}}=0$. This is similar to a deductible. At loss $\lambda_{t^{*}+1}$, a lump-sum payment of $\beta_{t^{*}+1}$ is made. This payment is less than the actual loss. Although the compensation increases as the loss increases, it does so at a slower rate than the loss. This means that the difference between the actual loss and the indemnity payment increases. This is similar to a coinsurance provision.

It is very interesting to see that by introducing a simple proportional loading factor to the premium, the optimal contract that will mitigate ex post moral hazard problems is one where traditional insurance instruments are found. A deductible provision in an insurance contract has been derived as optimal in two instances. First, when information is symmetric and there is a proportional loading factor, the optimal contract stipulates a deductible and full insurance above the deductible. Second, when there is adverse selection in the loss probability, the low risk agent would purchase a contract that has a deductible to signal that he is a low risk. Here, the deductible is obtained not only because there is a proportional loading of the premium, but also because there 
is ex post moral hazard. Coinsurance is typically used to control ex ante moral hazard: it increases the effort of the agent to avoid an accident. It is interesting to see that coinsurance is also useful to control ex post moral hazard.

Deductible and coinsurance provisions have been dismissed in the literature as ineffective against insurance fraud (see Dionne and Gagné, 1997). I show here such a conclusion may have been premature. It is true, however, that fraud is still committed and that some frauds remain undetected in the economy, but these are inevitable when the insurer cannot commit to an auditing strategy.

\subsection{Discussion}

There is no other contract in the literature where a systematic over-compensation of high losses is prescribed. Some existing contracts do, however, resemble the contract presented here. Two of these (Mookherjee and Png, 1989, and Bond and Crocker, 1997) predict some kind of overpayment. Although they use basically the same insurance fraud build-up model as is used here, the over-compensation schemes are quite different. In Bond and Crocker for example, it is the agent who suffers a very small loss who is over-compensated. The contract (shown in Figure 4) does not allow for overpayment of larger losses.

Figure 4: Bond and Crocker's optimal contract.

This contract has the same flavor as mine, shown in Figure 2. The two contracts stipulate 
that there is a distribution of losses (the smallest possible losses), where the agent receives a fixed payment, regardless of his actual loss. The insurer never audits losses in this range. Although the contracts are similar, they are not the same; Bond and Crocker show that the expected marginal utility in the no-auditing region is equal to the marginal utility in the no-accident state. I find that the expected marginal utility in the no-auditing region is greater than the marginal utility in the no-accident state. This means that ceteris paribus, Bond and Crocker's fixed payment must be greater than mine. On the other part of the distribution, the difference are somewhat greater. Bond and Crocker find that the agent must be perfectly compensated. This is not the case in my contract, where agents must be over-compensated for their loss.

This brings us to the paper by Mookherjee and Png (1989). They find that some agents who suffer higher losses can be over-compensated. Their findings appears to be very similar to my results. The difference is that Mookherjee and Png obtain over-compensation only if the agent is audited and tells the truth. In my contract, over-compensation is obtained as long as an agent suffers a high loss or commits fraud and is not caught.

Another major difference between the contract obtained in the literature and the one I derive here concerns the ability for the insurer to commit. Most contracts in the literature are derived assuming that the insurer is able to commit to an auditing strategy that ensures agent indifference between telling the truth and over-reporting his loss (normative approach). Using the epsilontruthfulness assumption (see Rasmussen, 1989, and Harrison, 1989), agents never commit fraud since they have nothing to gain by doing so. Unfortunately, the commitment assumption does not consider the fact that the players may wish to renegotiate the contract when time comes to implement some of its provisions.

The contracts found by Townsend (1979), and Bond and Crocker (1997) are not renegotiation proof. This means that, when the time comes for the insurer to audit a report from the agent, she may wish to inform the agent - who always tells the truth - that they should split the cost of auditing between them so that both would be better off. The contract I find, on the other hand, is renegotiation proof; there is no way that both players can be better off. This occurs mainly because each player implements a strategy that is a best response to the other's strategy.

Empirically, one may wonder whether the contract derived in the present paper is observed in reality. Crocker and Tennyson (1999) reach the conclusion that costly state falsification models, such as those of Lacker and Weinberg (1989) and Crocker and Morgan (1998), explain better the data than costly state verification models. They reach this conclusion based on the empirical finding that indemnity payments are increasing the claim, but at a decreasing rate (see Figure 5).

This distribution of indemnity payments as a function of losses is in opposition to costly state 
Figure 5: Indemnity Payments as a Function of Claimed Losses (Crocker and Tennyson, 1999).

verification models under full commitment where indemnity payments increase at the exact same rate as claims (see Figure 4). This in no longer true, however, when insurers cannot commit to an auditing strategy. Without commitment, the payment schedule is flatter than under full commitment (see Figure 2).

One aspect of the optimal contract which I present that does not seem to be observed empirically is over-compensation. Over-compensation is not observed only because the contract displayed in Figure 2 does not take into account loading factors. We see in Figure 3 when a loading factor is included that over-payment of losses no longer occurs. In fact the optimal costly state verification contract under non-commitment with $\lambda_{t^{*}}=0$ and a relatively large loading factor seem to match the empirical properties found by Crocker and Tennyson.

\section{Conclusion}

The purpose of this paper was to model a principal-agent relationship under a set of assumptions that were never made in the literature: costly state verification, ex post moral hazard, insurer non-commitment and a $T$-point distribution of losses. Focusing on the case of insurance claims build-up, the optimal contract for the agent that yields zero expected profits to the insurer has the property that losses greater than some cutoff point are over-compensated, while smaller losses are, on average, under-compensated. The amount of over- and under-compensation is such that 
the expected marginal utility in the accident state is exactly equal to the marginal utility of the policyholder in the no-accident state. This also means that the expected wealth in the accident state is less than the wealth in the no-accident state. Figure 2 displays the optimal contract.

A very interesting result of the paper is that the optimal contract may be represented as a combination of a deductible, a lump-sum payment and a coinsurance provision. This was made clearer in Figure 3 where a simple proportional premium loading factor is included in the model.

An important assumption that was made in this paper is that insurers were unable to commit to an auditing strategy. It is clear that if insurers could commit to an auditing strategy everybody would be better off (at least not worse off since one could commit not to commit). Whether insurers can commit to auditing strategies in reality is not clear. In reality, insurance contracts are renewed every year; which means that there exist reputation issues associated with such repeated games. These reputation issues may increase an insurer's ability to commit to an auditing strategy in the real world. Another tool available to insurers to increase their commitment to audit is to delegate auditing responsibilities to an outside body (such as Insurance Fraud Bureaus). This does not, however, solve entirely the problem since the outside body is faced with the same commitment problems as insurers themselves. Moreover, insurers must also verify the behavior of the outside body (the classic who watches the watcher problem), which includes a potential commitment problem as well.

As is the case for most models, the model developed here is a simplification of reality. One of the main aspects to be simplified is that all policyholders were assumed to have the same attitude toward crime. This does not seem to represent reality. Many people would never commit insurance fraud. Gordon (1990) and Cummins and Tennyson (1994) explain this, saying that it would bring about some intrinsic disutility which they called mental anguish. Other policyholders, on the other hand, would have no problem in engaging in such behavior. The question becomes: how do insurers differentiate between the two types of policyholders? Would there still be over-compensation for all? Will the more honest policyholder signal his honesty by accepting a compensation scheme that pays less in the low loss states (higher deductible), or less in the high loss states (less overcompensation)?

Another logical step would be to introduce ex ante moral hazard into the model in the same way as Dionne and Viala (1992). If agents can influence the state of the world by their actions, perhaps the optimal contract would be modified in such a way that no over-compensation ever occurs. 


\section{References}

1. Arnott, R. J. (1992). Moral Hazard and Competitive Insurance Markets. In Contributions to Insurance Economics, G. Dionne Ed., Kluwer Academic Publishers, Boston.

2. Baiman, S. and J. S. Demski (1980). Economically Optimal Performance Evaluation and Control Systems. Journal of Accounting Research.

3. Bond, E. W. and K. J. Crocker (1991). Smoking, Skydiving and Knitting: The Endogenous Categorization of Risks in Insurance Markets with Asymmetric Information. Journal of Political Economy, 99:177-200.

4. Bond, E. W. and K. J. Crocker (1997). Hardball and the Soft Touch: The Economics of Optimal Insurance Contracts with Costly State Verification and Endogenous Monitoring. Journal of Public Economics, 63:239-254.

5. Boyer, M. M. (2000). Insurance Taxation and Insurance Fraud. Journal of Public Economic Theory, 2:101-134.

6. Chang, C. (1990). The Dynamic Structure of Optimal Debt Contracts. Journal of Economic Theory, 52:68-86.

7. Crocker, K. J. and J. Morgan (1998). Is Honesty the Best Policy? Curtailing Insurance Fraud Through Optimal Contracts. Journal of Political Economy, 106:355-375.

8. Crocker, K. and S. Tennyson (1999). Costly State Falsification or Verification? Theory and Evidence from Bodily Injury Liability Claims. In Automobile Insurance: Road Safety, New Drivers, Risks, Insurance Fraud and Regulation, G. Dionne and C. Laberge-Nadeau Eds, Kluwer Academic Publishers, Boston.

9. Cummins, J. D. and S. Tennyson (1994). The Tort System «Lottery» and Insurance Fraud: Theory and Evidence from Automobile Insurance. Mimeo, University of Pennsylvania.

10. Dionne, G. and R. Gagné (1997). The Non-Optimality of Deductible Contracts Against Fraudulent Claims: An Empirical Evidence in Automobile Insurance. Working Paper 97-05, Risk Management Chair, HEC-Montréal.

11. Dionne, G. and P. Viala (1992). Optimal Design of Financial Contracts and Moral Hazard. Working paper 9219, Université de Montréal. 
12. Eeckhoudt, L. and C. Gollier (1995). Risk Evaluation, Management and Sharing. Harvester Wheatsheaf, Hertfordshire.

13. Gale, D. and M. Hellwig (1985). Incentive-Compatible Debt Contracts: The One-Period Problem. Review of Economic Studies, 52:647-663.

14. Gordon, J. P. F. (1990). Individual Morality and Reputation Costs as Deterrents to Tax Evasion. European Economic Review, 33:797-805.

15. Graetz, M. J., J. F. Reinganum and L. L. Wilde (1986). The Tax-Compliance Game: Toward an Interactive Theory of Law Enforcement. Journal of Law, Economics and Organization, $2: 1-32$.

16. Harrison, G. W. (1989). Theory and Misbehavior of First-Price Auctions. American Economic Review, 79:749-762.

17. Holmstrom, B. (1979). Moral Hazard and Observability. Bell Journal of Economics, 10:74-91.

18. Hoyt, R. E. (1989). The Effect of Insurance Fraud on the Economic System. Journal of Insurance Regulation, 8:304-315.

19. Kurtz, M. (1974). Experimental Approach to the Determination of the Demand for Public Goods. Journal of Public Economics, 3:329-348.

20. Khalil, F. (1997). Auditing without Commitment. Rand Journal of Economics, 28:629-640.

21. Khalil, F. and B. M. Parigi (1998). Loan Size as a Commitment Device. International Economic Review, forthcoming.

22. Lacker, J. M. and J. A. Weinberg, (1989). Optimal Contracts under Costly State Falsification.. Journal of Political Economy, 97:1345-1363.

23. Mookherjee, D. and I. Png (1989). Optimal Auditing, Insurance and Redistribution. Quarterly Journal of Economics, 104:205-228.

24. Persons, J. C. (1997). Liars Never Prosper? How Management Misrepresentation Reduces Monitoring Costs. Journal of Financial Intermediation, 6:269-306.

25. Picard, P. (1996). Auditing Claims in the Insurance Market with Fraud: The Credibility Issue. Journal of Public Economics, 63:27-56. 
26. Rasmussen, E. (1989). Games and Information: An Introduction to Game Theory. Blackwell, New York.

27. Ross, S. (1973). The Economic Theory of Agency: The Insurer's Problem. American Economic Review, 63:134-139.

28. Sanchez, I and J. Sobel (1993). Hierarchical Design and Enforcement of Income Tax Policies. Journal of Public Economics, 50:345-369.

29. Scotchmer, S. (1987). Audit Classes and Tax Enforcement Policy. American Economic Association Papers and Proceedings, 77:229-233.

30. Spence, A. M. and R. Zeckhauser (1971). Insurance, Information and Individual Action. American Economic Review, 61:380-387.

31. Townsend, R. M. (1979). Optimal Contracts and Competitive Markets with Costly State Verification. Journal of Economic Theory, 21:265-293.

32. Winter, R. A. (1992). Moral Hazard and Insurance Contracts. In Contributions to Insurance Economics, G.Dionne Ed., Kluwer Academic Publishers, Boston. 


\section{Appendix}

Proof of lemma 2. The way I will proceed is to show that no player has an incentive to deviate from the conjectured equilibrium. Let us start by showing that the agent has nothing to gain by deviating, and then proceed to show the same for the insurer.

\section{Agent}

Three cases are possible for the agent: He suffered loss $\lambda_{t}>\lambda_{t^{*}}$, loss $\lambda_{t}<\lambda_{t^{*}}$ and loss $\lambda_{t}=\lambda_{t^{*}}$.

$C A S E$ 1. Let us first look at the agent who suffers loss $\lambda_{t}<\lambda_{t^{*}}$. The conjectured equilibrium states that such an agent always tells the truth, that he is never audited and that he receives benefit $\beta_{t^{*}}$. His utility is then $U\left(A-\alpha-\lambda_{t}+\beta_{t^{*}}\right)$. Suppose he does not tell the truth and reports loss $\lambda_{t^{\prime}}<\lambda_{t^{*}}$ instead. In that case, his expected utility is the same as if he tells the truth, since he receives a flat payment $\left(\beta_{t^{*}}\right)$ for any report of a loss less than the cutoff point. Suppose now that he reports loss $\lambda_{t^{\prime}}>\lambda_{t^{*}}$. His expected utility from reporting loss $\lambda_{t^{\prime}}$ is

$$
\nu_{t^{\prime}} U\left(A-\alpha-\lambda_{t}+\beta_{t^{*}}-k\right)+\left(1-\nu_{t^{\prime}}\right) U\left(A-\alpha-\lambda_{t}+\beta_{t^{\prime}}\right)
$$

The agent has no reason to deviate if

$$
U\left(A-\alpha-\lambda_{t}+\beta_{t^{*}}\right) \geq \nu_{t^{\prime}} U\left(A-\alpha-\lambda_{t}+\beta_{t^{*}}-k\right)+\left(1-\nu_{t^{\prime}}\right) U\left(A-\alpha-\lambda_{t}+\beta_{t^{\prime}}\right)
$$

This can be rewritten as

$$
\nu_{t^{\prime}} \geq \frac{U\left(A-\alpha-\lambda_{t}+\beta_{t^{\prime}}\right)-U\left(A-\alpha-\lambda_{t}+\beta_{t^{*}}\right)}{U\left(A-\alpha-\lambda_{t}+\beta_{t^{\prime}}\right)-U\left(A-\alpha-\lambda_{t}+\beta_{t^{*}}-k\right)}
$$

We know what the insurer's auditing strategy is from the conjectured equilibrium (equation 8). Telling the truth is then optimal if and only if

$$
\frac{U\left(A-\alpha-\lambda_{t^{*}}+\beta_{t^{\prime}}\right)-U\left(A-\alpha-\lambda_{t^{*}}+\beta_{t^{*}}\right)}{U\left(A-\alpha-\lambda_{t^{*}}+\beta_{t^{\prime}}\right)-U\left(A-\alpha-\lambda_{t^{*}}+\beta_{t^{*}}-k\right)} \geq \frac{U\left(A-\alpha-\lambda_{t}+\beta_{t^{\prime}}\right)-U\left(A-\alpha-\lambda_{t}+\beta_{t^{*}}\right)}{U\left(A-\alpha-\lambda_{t}+\beta_{t^{\prime}}\right)-U\left(A-\alpha-\lambda_{t}+\beta_{t^{*}}-k\right)}
$$

We see that the only parameter that changes is the loss. Since $\lambda_{t}<\lambda_{t^{*}}(28)$ holds if $\frac{\partial \nu_{t^{\prime}}}{\partial \lambda} \leq 0$. We know that $\lambda_{t^{*}} \in\left[0, \lambda_{t^{\prime}}\right)$. It is easy to show that $\frac{\partial \nu_{t^{\prime}}}{\partial \lambda} \leq 0$ over $\lambda_{t^{*}} \in\left[0, \lambda_{t^{\prime}}\right)$ if and only if $R_{A} \leq P_{A}$, where $R_{A}$ and $P_{A}$ are the coefficients of absolute risk aversion and absolute prudence respectively.

First, we can show that

$$
\begin{aligned}
\Omega \frac{\partial \nu_{t^{\prime}}}{\partial \lambda}= & U^{\prime}\left(A-\alpha-\lambda_{t^{*}}+\beta_{t^{\prime}}\right)\left[U\left(A-\alpha-\lambda_{t^{*}}+\beta_{t^{*}}-k\right)-U\left(A-\alpha-\lambda_{t^{*}}+\beta_{t^{*}}\right)\right] \\
& +U^{\prime}\left(A-\alpha-\lambda_{t^{*}}+\beta_{t^{*}}\right)\left[U\left(A-\alpha-\lambda_{t^{*}}+\beta_{t^{\prime}}\right)-U\left(A-\alpha-\lambda_{t^{*}}+\beta_{t^{*}}-k\right)\right] \\
& -U^{\prime}\left(A-\alpha-\lambda_{t^{*}}+\beta_{t^{*}}-k\right)\left[U\left(A-\alpha-\lambda_{t^{*}}+\beta_{t^{\prime}}\right)-U\left(A-\alpha-\lambda_{t^{*}}+\beta_{t^{*}}\right)\right]
\end{aligned}
$$


where

$$
\Omega=\left[U\left(A-\alpha-\lambda_{t^{*}}+\beta_{t^{\prime}}\right)-U\left(A-\alpha-\lambda_{t^{*}}+\beta_{t^{*}}-k\right)\right]^{2}
$$

it is clear that $\frac{\partial \nu_{t^{\prime}}}{\partial \lambda} \leq 0$ when $k=0$. All that is left to show is that $\frac{\partial \nu_{t^{\prime}}}{\partial \lambda}$ is negative for all $k>0$. To do so, we need to show that $\Omega \frac{\partial \nu_{t^{\prime}}}{\partial \lambda}$ is decreasing in $k$. This occurs when

$$
\begin{aligned}
\frac{\partial\left(\Omega \frac{\partial \nu_{t^{\prime}}}{\partial \lambda}\right)}{\partial k}= & U^{\prime}\left(A-\alpha-\lambda_{t^{*}}+\beta_{t^{*}}-k\right)\left[U^{\prime}\left(A-\alpha-\lambda_{t^{*}}+\beta_{t^{*}}\right)-U^{\prime}\left(A-\alpha-\lambda_{t^{*}}+\beta_{t^{\prime}}\right)\right](31) \\
& +U^{\prime \prime}\left(A-\alpha-\lambda_{t^{*}}+\beta_{t^{*}}-k\right)\left[U\left(A-\alpha-\lambda_{t^{*}}+\beta_{t^{\prime}}\right)-U\left(A-\alpha-\lambda_{t^{*}}+\beta_{t^{*}}\right)\right]
\end{aligned}
$$

is negative. We then have that $\frac{\partial\left(\Omega \frac{\partial \nu_{t^{\prime}}}{\partial \lambda}\right)}{\partial k} \leq 0$ if and only if

$$
-\frac{U^{\prime}\left(A-\alpha-\lambda_{t^{*}}+\beta_{t^{*}}\right)-U^{\prime}\left(A-\alpha-\lambda_{t^{*}}+\beta_{t^{\prime}}\right)}{U\left(A-\alpha-\lambda_{t^{*}}+\beta_{t^{*}}\right)-U\left(A-\alpha-\lambda_{t^{*}}+\beta_{t^{\prime}}\right)} \leq-\frac{U^{\prime \prime}\left(A-\alpha-\lambda_{t^{*}}+\beta_{t^{*}}-k\right)}{U^{\prime}\left(A-\alpha-\lambda_{t^{*}}+\beta_{t^{*}}-k\right)}
$$

Using a Taylor expansion of the left hand side term, this inequality holds if $U^{\prime \prime \prime}()>$.0 , which is true by assumption.

$C A S E$ 2. The equilibrium also stipulates that the agent who suffers loss superior to $\lambda_{t}>$ $\lambda_{t^{*}}$ always tells the truth. Suppose not. It is clear that he will not under-report. His utility from under-reporting is $U\left(A-\alpha-\lambda_{t}+\beta_{t^{\prime}}\right)$ while his utility from telling the truth is $U\left(A-\alpha-\lambda_{t}+\beta_{t}\right)$. Since $\beta_{t^{\prime}}<\beta_{t}$, it is clear that the agent is better off telling the truth than under-reporting. Suppose the agent decides to over-report loss $\lambda_{t}$ as loss $\lambda_{t^{\prime}}, \lambda_{t^{*}}<\lambda_{t}<\lambda_{t^{\prime}}$. This is not optimal if and only if

$$
U\left(A-\alpha-\lambda_{t}+\beta_{t}\right) \geq \nu_{t^{\prime}} U\left(A-\alpha-\lambda_{t}+\beta_{t}-k\right)+\left(1-\nu_{t^{\prime}}\right) U\left(A-\alpha-\lambda_{t}+\beta_{t^{\prime}}\right)
$$

This occurs if and only if

$$
\nu_{t^{\prime}} \geq \frac{U\left(A-\alpha-\lambda_{t}+\beta_{t^{\prime}}\right)-U\left(A-\alpha-\lambda_{t}+\beta_{t}\right)}{U\left(A-\alpha-\lambda_{t}+\beta_{t^{\prime}}\right)-U\left(A-\alpha-\lambda_{t}+\beta_{t}-k\right)}
$$

We know what the insurer's auditing strategy is from the conjectured equilibrium (equation 8). Telling the truth is then optimal if and only if

$\frac{U\left(A-\alpha-\lambda_{t^{*}}+\beta_{t^{\prime}}\right)-U\left(A-\alpha-\lambda_{t^{*}}+\beta_{t^{*}}\right)}{U\left(A-\alpha-\lambda_{t^{*}}+\beta_{t^{\prime}}\right)-U\left(A-\alpha-\lambda_{t^{*}}+\beta_{t^{*}}-k\right)} \geq \frac{U\left(A-\alpha-\lambda_{t}+\beta_{t^{\prime}}\right)-U\left(A-\alpha-\lambda_{t}+\beta_{t}\right)}{U\left(A-\alpha-\lambda_{t}+\beta_{t^{\prime}}\right)-U\left(A-\alpha-\lambda_{t}+\beta_{t}-k\right)}$

which is equivalent to saying that

$$
\begin{aligned}
0 \leq & U\left(A-\alpha-\lambda_{t}+\beta_{t}\right)\left[U\left(A-\alpha-\lambda_{t^{*}}+\beta_{t^{\prime}}\right)-U\left(A-\alpha-\lambda_{t^{*}}+\beta_{t^{*}}-k\right)\right] \\
& +U\left(A-\alpha-\lambda_{t}+\beta_{t^{\prime}}\right)\left[U\left(A-\alpha-\lambda_{t^{*}}+\beta_{t^{*}}-k\right)-U\left(A-\alpha-\lambda_{t^{*}}+\beta_{t^{*}}\right)\right] \\
& +U\left(A-\alpha-\lambda_{t}+\beta_{t}-k\right)\left[U\left(A-\alpha-\lambda_{t^{*}}+\beta_{t^{*}}\right)-U\left(A-\alpha-\lambda_{t^{*}}+\beta_{t^{\prime}}\right)\right]
\end{aligned}
$$


Note that at $k=0$, the minimum value this parameter can take, this inequality holds with equality. Equation (36) is increasing in $k$ if and only if

$$
\begin{aligned}
0 \leq & -U^{\prime}\left(A-\alpha-\lambda_{t^{*}}+\beta_{t^{*}}-k\right)\left[U\left(A-\alpha-\lambda_{t}+\beta_{t^{\prime}}\right)-U\left(A-\alpha-\lambda_{t}+\beta_{t}\right)\right] \\
& +U^{\prime}\left(A-\alpha-\lambda_{t}+\beta_{t}-k\right)\left[U\left(A-\alpha-\lambda_{t^{*}}+\beta_{t^{\prime}}\right)-U\left(A-\alpha-\lambda_{t^{*}}+\beta_{t^{*}}\right)\right]
\end{aligned}
$$

Since $\lambda_{t^{*}}<\lambda_{t}<\lambda_{t^{\prime}}$, and since (37) holds when $\lambda_{t}=\lambda_{t^{*}}$ and when $\lambda_{t}=\lambda_{t^{\prime}}$, it follows that (36) is increasing in $k$ if and only if (37) is increasing in $\lambda_{t}$. This occurs only if

$$
\begin{aligned}
0 \leq & U^{\prime}\left(A-\alpha-\lambda_{t^{*}}+\beta_{t^{*}}-k\right)\left[U^{\prime}\left(A-\alpha-\lambda_{t}+\beta_{t^{\prime}}\right)+\left(\frac{\partial \beta_{t}}{\partial \lambda_{t}}-1\right) U^{\prime}\left(A-\alpha-\lambda_{t}+\beta_{t}\right)\right] \\
& +\left(\frac{\partial \beta_{t}}{\partial \lambda_{t}}-1\right) U^{\prime \prime}\left(A-\alpha-\lambda_{t}+\beta_{t}-k\right)\left[U\left(A-\alpha-\lambda_{t^{*}}+\beta_{t^{\prime}}\right)-U\left(A-\alpha-\lambda_{t^{*}}+\beta_{t^{*}}\right)\right]
\end{aligned}
$$

which we may rewrite as

$$
\left(\frac{\partial \beta_{t}}{\partial \lambda_{t}}-1\right) \Gamma \geq-U^{\prime}\left(A-\alpha-\lambda_{t^{*}}+\beta_{t^{*}}-k\right) U^{\prime}\left(A-\alpha-\lambda_{t}+\beta_{t^{\prime}}\right)
$$

where

$$
\begin{aligned}
\Gamma= & U^{\prime}\left(A-\alpha-\lambda_{t^{*}}+\beta_{t^{*}}-k\right) U^{\prime}\left(A-\alpha-\lambda_{t}+\beta_{t}\right) \\
& +U^{\prime \prime}\left(A-\alpha-\lambda_{t}+\beta_{t}-k\right)\left[U\left(A-\alpha-\lambda_{t^{*}}+\beta_{t^{\prime}}\right)-U\left(A-\alpha-\lambda_{t^{*}}+\beta_{t^{*}}\right)\right]
\end{aligned}
$$

Suppose first that $\Gamma>0$. It can then be shown that (39) holds if and only if $\frac{\partial \beta_{t}}{\partial \lambda_{t}}>0$. On the other hand, suppose that $\Gamma<0$. It can then be shown that (39) holds if and only if $\frac{\partial \beta_{t}}{\partial \lambda_{t}}<1$. Since we assumed $\frac{\partial \beta_{t}}{\partial \lambda_{t}} \in(0,1)$ to be true, (37) is increasing in $\lambda_{t}$ for any $\lambda_{t} \in\left(\lambda_{t^{*}}, \lambda_{t^{\prime}}\right)$. It follows that (36) is defined and positive for any value of $k$; which means that (36) increases monotonically in $k$.

$C A S E$ 3. The final step for the agent is to show that he has nothing to gain by deviating if his loss is equal to $\lambda_{t}=\lambda_{t^{*}}$. For him to be better off not deviating, it has to be that

$$
\begin{array}{r}
0 \leq \eta_{t^{*} t^{\prime}}\left[\begin{array}{c}
\nu_{t^{\prime}} U\left(A-\alpha-\lambda_{t^{*}}+\beta_{t^{*}}-k\right) \\
+\left(1-\nu_{t^{\prime}}\right) U\left(A-\alpha-\lambda_{t^{*}}+\beta_{t^{\prime}}\right)
\end{array}\right]+\left(1-\eta_{t^{*} t^{\prime}}\right) U\left(A-\alpha-\lambda_{t^{*}}+\beta_{t^{*}}\right) \\
-\widetilde{\eta_{t^{*} t^{\prime}}}\left[\begin{array}{c}
\nu_{t^{\prime}} U\left(A-\alpha-\lambda_{t^{*}}+\beta_{t^{*}}-k\right) \\
+\left(1-\nu_{t^{\prime}}\right) U\left(A-\alpha-\lambda_{t^{*}}+\beta_{t^{\prime}}\right)
\end{array}\right]-\left(1-\widetilde{\eta_{t^{*} t^{\prime}}}\right) U\left(A-\alpha-\lambda_{t^{*}}+\beta_{t^{*}}\right)
\end{array}
$$

where $\eta_{t^{*} t^{\prime}}$ is the conjectured equilibrium probability that the agent with loss $\lambda_{t^{*}}$ reports loss $\lambda_{t^{\prime}}>\lambda_{t^{*}}$, and $\widetilde{\eta_{t^{*} t^{\prime}}}$ is some other probability. What I want to show is that there is nothing to gain from using a probability of lying other than $\eta_{t^{*} t^{\prime}}$. If we combine the terms in the previous equation, we obtain that the agent has nothing to gain by deviating if and only if

$$
\begin{aligned}
0 \leq & \left(\eta_{t^{*} t^{\prime}}-\widetilde{\eta_{t^{*} t^{\prime}}}\right)\left[\nu_{t^{\prime}} U\left(A-\alpha-\lambda_{t^{*}}+\beta_{t^{*}}-k\right)+\left(1-\nu_{t^{\prime}}\right) U\left(A-\alpha-\lambda_{t^{*}}+\beta_{t^{\prime}}\right)\right] \\
& -\left(\eta_{t^{*} t^{\prime}}-\widetilde{\eta_{t^{*} t^{\prime}}}\right) U\left(A-\alpha-\lambda_{t^{*}}+\beta_{t^{*}}\right)
\end{aligned}
$$


We know from (8) what the insurer's auditing strategy is, $\nu_{t^{\prime}}$. Substituting that value in (42) and simplifying gives us

$$
\begin{aligned}
0 \leq & -\left(\eta_{t^{*} t^{\prime}}-\widetilde{\eta_{t^{*} t^{\prime}}}\right)\left[U\left(A-\alpha-\lambda_{t^{*}}+\beta_{t}\right)-U\left(A-\alpha-\lambda_{t^{*}}+\beta_{t^{*}}\right)\right] \\
& +\left(\eta_{t^{*} t^{\prime}}-\widetilde{\eta_{t^{*} t^{\prime}}}\right)\left[U\left(A-\alpha-\lambda_{t^{*}}+\beta_{t^{\prime}}\right)-U\left(A-\alpha-\lambda_{t^{*}}+\beta_{t^{*}}\right)\right]
\end{aligned}
$$

which always holds with equality. Therefore the agent who suffered $\lambda_{t^{*}}$ has no reason to deviate from his conjectured strategy since he has nothing to gain from it. I have thus shown that the agent has nothing to gain by deviating from his conjectured equilibrium strategy.

\section{Insurer}

I will use the same approach to show that the insurer has no incentive to deviate from the conjectured equilibrium. For the insurer there are two possibilities that need be considered: 1auditing a reported loss less than or equal to $\lambda_{t^{*}}$; and 2- auditing a reported loss greater than $\lambda_{t^{*}}$.

The conjectured equilibrium stipulates that the probability of auditing a reported loss less than or equal to $\lambda_{t^{*}}$ is equal to zero. Suppose not. Suppose the insurer audits some of those reports with some probability. By not auditing the insurer is guaranteed to pay $\beta_{t^{*}}$. By auditing, the insurer still pays $\beta_{t^{*}}$, since the agent always tells the truth if his loss is less than $\lambda_{t^{*}}$, but she also incurs an auditing cost $c$. It is therefore clear that she is better never to audit.

In the second case, suppose the insurer audits reported loss $\lambda_{t^{\prime}}$ with probability $\widetilde{\nu_{t^{\prime}}}$ instead of $\nu_{t^{\prime}}$. This is not profitable to the insurer if and only if

$$
\begin{aligned}
0 \leq & \nu_{t^{\prime}}\left(-c-\gamma_{t^{\prime}} \beta_{t^{\prime}}-\left(1-\gamma_{t^{\prime}}\right) \beta_{t^{*}}\right)+\left(1-\nu_{t^{\prime}}\right)\left(-\beta_{t^{\prime}}\right) \\
& -\widetilde{\nu_{t^{\prime}}}\left(-c-\gamma_{t^{\prime}} \beta_{t^{\prime}}-\left(1-\gamma_{t^{\prime}}\right) \beta_{t^{*}}\right)-\left(1-\widetilde{\nu_{t^{\prime}}}\right)\left(-\beta_{t^{\prime}}\right)
\end{aligned}
$$

where $\gamma_{t^{\prime}}$ is the ex post belief that the insurer assigns to the fact that a reported loss of $\lambda_{t^{\prime}}$ is truthful. Combining terms yields

$$
0 \leq\left(\nu_{t^{\prime}}-\widetilde{\nu_{t^{\prime}}}\right)\left(-c+\left(1-\gamma_{t^{\prime}}\right)\left(\beta_{t^{\prime}}-\beta_{t^{*}}\right)\right)
$$

From Table 1 we know what $\gamma_{t^{\prime}}$ is in the conjectured equilibrium for $t^{\prime}>t^{*}$. Substituting in (45) yields

$$
0 \leq\left(\nu_{t^{\prime}}-\widetilde{\nu_{t^{\prime}}}\right)\left(-c+\left(1-\frac{\beta_{t}-\beta_{t^{*}}-c}{\beta_{t}-\beta_{t^{*}}}\right)\left(\beta_{t^{\prime}}-\beta_{t^{*}}\right)\right)
$$

If we simplify all the terms, we obtain that the statement is correct. Therefore, there is nothing to gain for the insurer by deviating from her conjectured strategy. Since it is never profitable for the insurer to deviate, her strategy is therefore a best response to the agent's strategy. 
Since neither the agent nor the insurer have any reason to deviate, it has to be that the conjectured equilibrium is indeed a Perfect Bayesian Nash equilibrium. This completes the proof that the conjectured equilibrium is indeed a Nash equilibrium.

Proof of lemma 3. Let us rewrite (9) as

$$
\alpha=\left(\begin{array}{c}
\text { Payment if the agent is not caught committing fraud }(N C D) \\
+ \text { Payment if the agent is caught committing fraud }(C D) \\
+ \text { cost of the auditing strategy }(C A S)
\end{array}\right)
$$

We know from (7) that all agents who suffer loss $\lambda_{t}>\lambda_{t^{*}}$ always tell the truth. Also, all those who suffer loss $\lambda_{t}<\lambda_{t^{*}}$ always report $\lambda_{t^{*}}$. We also know that a report of loss of size $\lambda_{t^{*}}$ is never audited from (8). We then can write each of the three terms in (47). NCD can be written as

$$
N C D=\pi\left[\sum_{t=t^{*}+1}^{T} \rho_{t} \beta_{t}+\rho_{t^{*}} \sum_{t=t^{*}}^{T} \eta_{t t^{*}}\left(1-\nu_{t}\right) \beta_{t}+\sum_{t=1}^{t^{*}-1} \rho_{t} \beta_{t^{*}}\right]
$$

The first term of (48) is the sum of the payments made to those who suffered a loss greater than the cutoff point. We know that those agents report their loss truthfully. The second term is the sum of the payments made to the agent who plays a mixed strategy between telling the truth and over-reporting. Those payments are made as if the report is truthful, since the over-reporting agent is not audited. Finally the last term is the sum of the payments made to those agents who suffered loss less than the cutoff point, and who always report the loss value associated with the cutoff point. Those reports are never audited since the PBNE requires that a report equal to the cutoff point is never audited.

$C D$ is equal to

$$
C D=\pi \rho_{t^{*}} \sum_{j=t^{*}}^{T} \eta_{j t^{*}} \nu_{j} \beta_{t^{*}}
$$

Here, only the agent who plays a mixed strategy that involves telling the truth and over-reporting can ever be caught. All other agents either always tell the truth, or report a loss that is never audited. Finally, $C A S$ is equal to

$$
C A S=\pi c \sum_{t=t^{*}+1}^{T} \nu_{t}\left(\rho_{t}+\rho_{t^{*}} \eta_{t t^{*}}\right)
$$

The insurer must pay the audit cost only for those reports that are audited. Two kinds of report can be audited. There is the truthful report of a loss greater than $\lambda_{t^{*}}$, and the exaggerated report of the agent who suffered loss $\lambda_{t^{*}}$. Since the insurer cannot a priori establish a difference between a truthful report of loss $\lambda_{t}>\lambda_{t^{*}}$ and an exaggerated report of true loss $\lambda_{t^{*}}$, she will need to audit each report with the same probability. 
If we put (48), (49) and (50) together, and combine the terms, we obtain

$$
\begin{aligned}
\frac{\alpha}{\pi}= & \sum_{t=t^{*}+1}^{T} \rho_{t} \beta_{t}+\rho_{t^{*}} \sum_{t=t^{*}}^{T} \eta_{t t^{*}}\left(1-\nu_{t}\right) \beta_{t}+\sum_{t=1}^{t^{*}-1} \rho_{t} \beta_{t^{*}} \\
& +\rho_{t^{*}} \sum_{j=t^{*}}^{T} \eta_{j t^{*}} \nu_{j} \beta_{t^{*}}+c \sum_{t=t^{*}+1}^{T} \nu_{t}\left(\rho_{t}+\rho_{t^{*}} \eta_{t t^{*}}\right)
\end{aligned}
$$

We can simplify (51) by substituting for $\eta_{i j}$ given in (7). This yields

$$
\begin{aligned}
\frac{\alpha}{\pi}= & \sum_{t=t^{*}+1}^{T} \rho_{t} \beta_{t}+\sum_{t=1}^{t^{*}} \rho_{t} \beta_{t^{*}}+\sum_{t=t^{*}+1}^{T} \rho_{t^{*}}\left(\frac{c}{\beta_{t}-\beta_{t^{*}}-c}\right) \frac{\rho_{t}}{\rho_{t^{*}}}\left(\beta_{t}-\beta_{t^{*}}\right) \\
& +\sum_{t=t^{*}+1}^{T} \rho_{t} \nu_{t} c-\sum_{t=t^{*}+1}^{T} \rho_{t^{*}} \nu_{t}\left(\frac{c}{\beta_{t}-\beta_{t^{*}}-c}\right) \frac{\rho_{t}}{\rho_{t^{*}}}\left(\beta_{t}-\beta_{t^{*}}-c\right)
\end{aligned}
$$

It is clear that the last two terms sum to zero. We are then able to rewrite $(52) \mathrm{as}^{14}$

$$
\alpha=\pi\left[\beta_{t^{*}}+\sum_{t=t^{*}+1}^{T} \rho_{t} \frac{\left(\beta_{t}-\beta_{t^{*}}\right)^{2}}{\left(\beta_{t}-\beta_{t^{*}}-c\right)}\right]
$$

It is interesting to note that the agent's wealth, his risk aversion and the possible penalty do not affect the price directly.

From lemma 1, all payments to those policyholders who suffered a loss less than $\lambda_{t^{*}}$ receive the same payment, $\beta_{t^{*}}$. They gain nothing by engaging in insurance fraud. We can then restrict the analysis to the $T-t^{*}+1$ larger $\beta$ 's. The number of decision variables is thus reduced from $T+1$ to $T-t^{*}+2$. By substituting (7) and (8) in (6), the problem becomes

$$
\max _{\beta_{t^{*}, \beta_{t^{*}+1}, \ldots, \beta_{T}, \alpha}} E U(.)=(1-\pi) U(A-\alpha)+\sum_{t=1}^{t^{*}-1} \pi \rho_{t} U\left(A-\alpha-\lambda_{t}+\beta_{t^{*}}\right)
$$

\footnotetext{
${ }^{14}$ We can rewrite $(52)$ as

$$
\alpha=\sum_{t=t^{*}+1}^{T} \pi \rho_{t}\left[\beta_{t}+\frac{c\left(\beta_{t}-\beta_{t^{*}}\right)}{\left(\beta_{t}-\beta_{t^{*}}-c\right)}\right]+\sum_{t=1}^{t^{*}} \pi \rho_{t} \beta_{t^{*}}
$$

which is independent of the auditing strategy of the insurer. Note that

$$
\sum_{t=1}^{t^{*}} \pi \rho_{t} \beta_{t^{*}}=\pi\left(1-\sum_{t=t^{*}+1}^{T} \rho_{t}\right) \beta_{t^{*}}
$$

Substituting in the previous equation yields

$$
\alpha=\sum_{t=t^{*}+1}^{T} \pi \rho_{t}\left[\beta_{t}+\frac{c\left(\beta_{t}-\beta_{t^{*}}\right)}{\left(\beta_{t}-\beta_{t^{*}}-c\right)}\right]+\pi \beta_{t^{*}}-\sum_{t=t^{*}+1}^{T} \pi \rho_{t} \beta_{t^{*}}
$$
}

Combining the summation terms and simplifying gives us (53). 


$$
\begin{aligned}
& +\sum_{t=t^{*}+1}^{T} \pi \rho_{t} U\left(A-\alpha-\lambda_{t}+\beta_{t}\right)+\pi \rho_{t^{*}} U\left(A-\alpha-\lambda_{t^{*}}+\beta_{t^{*}}\right) \\
& +\pi \rho_{t^{*}} \sum_{t=t^{*}+1}^{T}\left(\frac{c}{\beta_{t}-\beta_{t^{*}}-c}\right)\left(\frac{\rho_{t}}{\rho_{t^{*}}}\right)\left(1-\nu_{t}\right) U\left(A-\alpha-\lambda_{t^{*}}+\beta_{t}\right) \\
& +\pi \rho_{t^{*}} \sum_{t=t^{*}+1}^{T}\left(\frac{c}{\beta_{t}-\beta_{t^{*}}-c}\right)\left(\frac{\rho_{t}}{\rho_{t^{*}}}\right) \nu_{t} U\left(A-\alpha-\lambda_{t^{*}}+\beta_{t}-k\right) \\
& -\pi \rho_{t^{*}} \sum_{t=t^{*}+1}^{T}\left(\frac{c}{\beta_{t}-\beta_{t^{*}}-c}\right)\left(\frac{\rho_{t}}{\rho_{t^{*}}}\right) U\left(A-\alpha-\lambda_{t^{*}}+\beta_{t^{*}}\right)
\end{aligned}
$$

Note that the last three lines sum to zero. The entire problem can then be written as

$$
\begin{aligned}
\max _{\beta_{t^{*}}, \beta_{t^{*}+1}, \ldots, \beta_{T}, \alpha} E U(.)= & (1-\pi) U(A-\alpha)+\sum_{t=1}^{t^{*}} \pi \rho_{t} U\left(A-\alpha-\lambda_{t}+\beta_{t^{*}}\right) \\
& +\sum_{t=t^{*}+1}^{T} \pi \rho_{t} U\left(A-\alpha-\lambda_{t}+\beta_{t}\right)
\end{aligned}
$$

subject to

$$
\alpha=\pi\left[\beta_{t^{*}}+\sum_{t=t^{*}+1}^{T} \rho_{t} \frac{\left(\beta_{t}-\beta_{t^{*}}\right)^{2}}{\left(\beta_{t}-\beta_{t^{*}}-c\right)}\right]
$$

and

$$
E U^{*}(Y) \geq(1-\pi) U(A)+\pi \sum_{t=1}^{T} \rho_{t} U\left(A-\lambda_{t}\right)
$$

Substituting (56) in (55) completes the proof.•

$\underline{\text { Proof of proposition } 1}$ In the general case where $\lambda_{1}<\lambda_{t^{\prime}}=\lambda_{t^{*}}$, this is obvious since all agents with loss $\lambda_{t}<\lambda_{t^{*}}$ report the truth, are never audited, and receive a flat payment of $\beta_{t^{*}}$. By definition, this contradicts the perfect income smoothing premise. In the case of $\lambda_{1}=\lambda_{t^{\prime}}=\lambda_{t^{*}}$, however, this is less obvious. When $\lambda_{1}=\lambda_{t^{\prime}}=\lambda_{t^{*}}$, (13) and (14) become

$$
\frac{\pi \rho_{1} U^{\prime}\left(A-\alpha-\lambda_{1}+\beta_{1}\right)}{E U^{\prime}(.)}=\pi-\sum_{j=2}^{T} \frac{\partial \alpha}{\partial \beta_{j}}
$$

and

$$
\frac{\pi \rho_{j} U^{\prime}\left(A-\alpha-\lambda_{j}+\beta_{j}\right)}{E U^{\prime}(.)}=\frac{\partial \alpha}{\partial \beta_{j}} \quad \forall j \geq 2
$$

where $\rho_{1}=1-\sum_{j=2}^{T} \rho_{j}$. To continue the proof, I need to show that

$$
\frac{\partial \alpha}{\partial \beta_{j}}\left(\frac{1}{\pi \rho_{j}}\right)=\frac{\left(\beta_{j}-\beta_{1}\right)\left(\beta_{j}-\beta_{1}-2 c\right)}{\left(\beta_{j}-\beta_{1}-c\right)^{2}}<1
$$


where the inequality is strict. Expanding terms yields

$$
\left(\beta_{j}-\beta_{1}\right)^{2}-2 c\left(\beta_{j}-\beta_{1}\right)+c^{2}>\left(\beta_{j}-\beta_{1}\right)^{2}-2 c\left(\beta_{j}-\beta_{1}\right)
$$

Which is true by the assumption that $c>0$ (strictly). This means that (59) is such that

$$
\frac{U^{\prime}\left(A-\alpha-\lambda_{j}+\beta_{j}\right)}{E U^{\prime}(.)}<1 \quad \forall j \geq 2
$$

I also need to show that

$$
\frac{1}{\pi \rho_{1}}\left(\pi-\sum_{t=2}^{T} \frac{\partial \alpha}{\partial \beta_{t}}\right)>1
$$

where the inequality is strict. By rearranging the terms and substituting in for $\frac{\partial \alpha}{\partial \beta_{t}}$ yields

$$
\pi\left(1-\rho_{1}\right)>\sum_{t=2}^{T} \pi \rho_{t} \frac{\left(\beta_{j}-\beta_{1}\right)\left(\beta_{j}-\beta_{1}-2 c\right)}{\left(\beta_{j}-\beta_{1}-c\right)^{2}}
$$

Since $\rho_{1}=1-\sum_{t=2}^{T} \rho_{t}$. We can then rewrite $(64)$ as

$$
\sum_{t=2}^{T} \rho_{t}>\sum_{t=2}^{T} \rho_{t} \frac{\left(\beta_{j}-\beta_{1}\right)\left(\beta_{j}-\beta_{1}-2 c\right)}{\left(\beta_{j}-\beta_{1}-c\right)^{2}}
$$

and

$$
\sum_{t=2}^{T} \rho_{t}\left[1-\frac{\left(\beta_{j}-\beta_{1}\right)\left(\beta_{j}-\beta_{1}-2 c\right)}{\left(\beta_{j}-\beta_{1}-c\right)^{2}}\right]>0
$$

which is obviously true since the term in bracket is positive whenever $c$ is positive. This means that

$$
\frac{U^{\prime}\left(A-\alpha-\lambda_{1}+\beta_{1}\right)}{E U^{\prime}(.)}=\frac{1}{\pi \rho_{1}}\left(\pi-\sum_{j=2}^{T} \frac{\partial \alpha}{\partial \beta_{j}}\right)>1
$$

By combining equations (67) and (62), it is clear that

$$
\frac{U^{\prime}\left(A-\alpha-\lambda_{1}+\beta_{1}\right)}{E U^{\prime}(.)}>1>\frac{U^{\prime}\left(A-\alpha-\lambda_{j}+\beta_{j}\right)}{E U^{\prime}(.)}
$$

which leads to

$$
U^{\prime}\left(A-\alpha-\lambda_{1}+\beta_{1}\right)>U^{\prime}\left(A-\alpha-\lambda_{j}+\beta_{j}\right)
$$

and

$$
\beta_{1}-\lambda_{1}<\beta_{j}-\lambda_{j}
$$


where the inequality is strict. It must therefore be that $\beta_{j}$ cannot equal $\lambda_{i}$ if $\beta_{1}$ equals $\lambda_{1}$, and vice versa.

$\underline{\text { Proof of proposition } 2}$ What I want to show is that $\frac{\partial \beta}{\partial \lambda}<1$ for all $\lambda_{t}>\lambda_{t^{*}}$. This is equivalent to

$$
U^{\prime}\left(A-\alpha-\lambda_{j}+\beta_{j}\right)>U^{\prime}\left(A-\alpha-\lambda_{j+1}+\beta_{j+1}\right)
$$

Using the necessary conditions displayed in (13) and (14), (71) holds if and only if

$$
\frac{E U^{\prime}(.)}{\pi \rho_{j}} \frac{\partial \alpha}{\partial \beta_{j}}<\frac{E U^{\prime}(.)}{\pi \rho_{j+1}} \frac{\partial \alpha}{\partial \beta_{j+1}}
$$

Substituting for $\frac{\partial \alpha}{\partial \beta_{j}}$ and $\frac{\partial \alpha}{\partial \beta_{j+1}}$, and simplifying yields

$$
\frac{\left(\beta_{j}-\beta_{t^{*}}\right)\left(\beta_{j}-\beta_{t^{*}}-2 c\right)}{\left(\beta_{j}-\beta_{t^{*}}-c\right)^{2}}<\frac{\left(\beta_{j+1}-\beta_{t^{*}}\right)\left(\beta_{j+1}-\beta_{t^{*}}-2 c\right)}{\left(\beta_{j+1}-\beta_{t^{*}}-c\right)^{2}}
$$

Equation (73) holds if and only if

$$
\frac{\partial}{\partial \beta_{j}}\left[\frac{\left(\beta_{j}-\beta_{t^{*}}\right)\left(\beta_{j}-\beta_{t^{*}}-2 c\right)}{\left(\beta_{j}-\beta_{t^{*}}-c\right)^{2}}\right]>0
$$

which occurs if and only if $\frac{\partial \alpha}{\partial \beta_{j}}<\pi \rho_{j}$, which we know to be true from proposition 1 (equation 60$)$.

Proof of theorem 2 Substituting (14) in (13) yields

$$
\frac{\pi \sum_{t=1}^{t^{*}} \rho_{t} U^{\prime}\left(A-\alpha-\lambda_{t}+\beta_{t^{*}}\right)}{E U^{\prime}(.)}=\pi-\sum_{t=t^{*}+1}^{T} \frac{\pi \rho_{t} U^{\prime}\left(A-\alpha-\lambda_{t}+\beta_{t}\right)}{E U^{\prime}(.)}
$$

Expanding $E U^{\prime}($.$) given in (15) and simplifying the terms generate$

$$
U^{\prime}(A-\alpha)=\sum_{t=1}^{t^{*}} \rho_{t} U^{\prime}\left(A-\alpha-\lambda_{t}+\beta_{t^{*}}\right)+\sum_{t=t^{*}+1}^{T} \rho_{t} U^{\prime}\left(A-\alpha-\lambda_{t}+\beta_{t}\right)
$$

The marginal utility in the no-accident state (left-hand side) is thus equal to the expected marginal utility in the accident state (right-hand side).

$\underline{\text { Proof of corollary } 1}$ From (14) we obtained that for all $t>t^{*}$,

$$
\pi \rho_{t} U^{\prime}\left(A-\alpha-\lambda_{t}+\beta_{t}\right)=E U^{\prime}(.) \frac{\partial \alpha}{\partial \beta_{t}}
$$

From theorem 2, we can rewrite $E U^{\prime}($.$) as U^{\prime}(A-\alpha)$. This yields

$$
\pi \rho_{t} U^{\prime}\left(A-\alpha-\lambda_{t}+\beta_{t}\right)=U^{\prime}(A-\alpha) \frac{\partial \alpha}{\partial \beta_{t}}
$$


We know from (60) that $\frac{\partial \alpha}{\partial \beta_{j}}<\pi \rho_{j}$. Thus

$$
U^{\prime}\left(A-\alpha-\lambda_{t}+\beta_{t}\right)=U^{\prime}(A-\alpha)\left(\frac{1}{\pi \rho_{t}}\right) \frac{\partial \alpha}{\partial \beta_{t}}<U^{\prime}(A-\alpha)
$$

which means that $\beta_{t}>\lambda_{t} \forall \lambda_{t}>\lambda_{t^{*}}$. This completes the first part of the proof. In the second part, we have that

$$
U^{\prime}(A-\alpha)=\sum_{t=1}^{t^{*}} \rho_{t} U^{\prime}\left(A-\alpha-\lambda_{t}+\beta_{t^{*}}\right)+\sum_{t=t^{*}+1}^{T} \rho_{j} U^{\prime}\left(A-\alpha-\lambda_{j}+\beta_{j}\right)
$$

which can also be written as

$$
\sum_{t=t^{*}+1}^{\sum_{t} U^{\prime}(A-\alpha)} \sum_{t=t^{*}+1}^{T} \rho_{t} U^{\prime}\left(A-\alpha-\lambda_{t}+\beta_{t}\right) \quad=\begin{gathered}
\sum_{t=1}^{t^{*}} \rho_{t} U^{\prime}\left(A-\alpha-\lambda_{t}+\beta_{t^{*}}\right) \\
-\sum_{t=1}^{t^{*}} \rho_{t} U^{\prime}(A-\alpha)
\end{gathered}
$$

We know from (79) that $\beta_{t}>\lambda_{t} \forall \lambda_{t}>\lambda_{t^{*}}$. Thus the left hand side of (81) is positive. This means that

$$
\sum_{t=1}^{t^{*}} \rho_{t} U^{\prime}\left(A-\alpha-\lambda_{t}+\beta_{t^{*}}\right)-\sum_{t=1}^{t^{*}} U^{\prime}(A-\alpha)>0
$$

This equation tells us that the expected marginal utility in the non-audited states is greater than the marginal utility in the no-loss state. This means that there is at least one loss whose coverage is smaller than the loss itself. The final step is to show that loss $\lambda_{t^{*}}$ fills that requirement. Since $U^{\prime \prime}()<$.0 , it follows that $U^{\prime}\left(A-\alpha-\lambda_{t}+\beta_{t^{*}}\right)<U^{\prime}\left(A-\alpha-\lambda_{t+1}+\beta_{t^{*}}\right)$. The greatest possible reported loss that is not audited is $\lambda_{t^{*}}$. This means that ultimately, $\beta_{t^{*}}<\lambda_{t^{*}} \bullet$

Proof of proposition 3. Substituting (24) into (23), yields an unconstrained problem with $T-t^{*}+1$ variables.

$$
\begin{aligned}
\max _{\beta_{t^{*}, \beta_{t^{*}+1}, \ldots, \beta_{T}} E U(.)=} & (1-\pi) U\left(A-(1+m) \pi\left[\beta_{t^{*}}+\sum_{t=t^{*}+1}^{T} \rho_{t} \frac{\left(\beta_{t}-\beta_{t^{*}}\right)^{2}}{\left(\beta_{t}-\beta_{t^{*}}-c\right)}\right]\right) \\
& +\sum_{t=1}^{t^{*}} \pi \rho_{t} U\left(A-(1+m) \pi\left[\beta_{t^{*}}+\sum_{t=t^{*}+1}^{T} \rho_{t} \frac{\left(\beta_{t}-\beta_{t^{*}}\right)^{2}}{\left(\beta_{t}-\beta_{t^{*}}-c\right)}\right]-\lambda_{t}+\beta_{t^{*}}\right) \\
& +\sum_{t=t^{*}+1}^{T} \pi \rho_{t} U\left(A-(1+m) \pi\left[\beta_{t^{*}}+\sum_{t=t^{*}+1}^{T} \rho_{t} \frac{\left(\beta_{t}-\beta_{t^{*}}\right)^{2}}{\left(\beta_{t}-\beta_{t^{*}}-c\right)}\right]-\lambda_{t}+\beta_{t}\right)
\end{aligned}
$$

Recall that all payments to those agents who suffered a loss smaller than $\lambda_{t^{*}}$ receive the same payment, $\beta_{t^{*}}$. The first order conditions of (83) are

$$
\begin{aligned}
\frac{\partial}{\partial \beta_{t^{*}}}= & 0=-(1-\pi) U^{\prime}(A-(1+m) \alpha)(1+m) \frac{\partial \alpha}{\partial \beta_{t^{*}}} \\
& -\sum_{t=t^{*}+1}^{T} \pi \rho_{t} U\left(A-(1+m) \alpha-\lambda_{t}+\beta_{t}\right)(1+m) \frac{\partial \alpha}{\partial \beta_{t^{*}}} \\
& +\sum_{t=1}^{t^{*}} \pi \rho_{t} U^{\prime}\left(A-(1+m) \alpha-\lambda_{t}+\beta_{t^{*}}\right)\left(1-(1+m) \frac{\partial \alpha}{\partial \beta_{t^{*}}}\right)
\end{aligned}
$$


and, $\forall j \geq t^{*}+1$

$$
\begin{aligned}
\frac{\partial}{\partial \beta_{j}}= & 0=\pi \rho_{j} U^{\prime}\left(A-\alpha-\lambda_{j}+\beta_{j}\right)-(1-\pi) U^{\prime}(A-\alpha)(1+m) \frac{\partial \alpha}{\partial \beta_{j}} \\
& -\sum_{t=1}^{t^{*}} \pi \rho_{t} U^{\prime}\left(A-\alpha-\lambda_{t}+\beta_{t^{*}}\right)(1+m) \frac{\partial \alpha}{\partial \beta_{j}} \\
& -\sum_{t=t^{*}+1}^{T} \pi \rho_{t} U\left(A-\alpha-\lambda_{t}+\beta_{t}\right)(1+m) \frac{\partial \alpha}{\partial \beta_{j}}
\end{aligned}
$$

where the partial derivatives of the premium with respect to coverage are given by

$$
\begin{gathered}
\frac{\partial \alpha}{\partial \beta_{t^{*}}}=\pi \sum_{t=1}^{t^{*}} \rho_{t}+\pi \sum_{t=t^{*}+1}^{T} \rho_{t}\left(\frac{c}{\beta_{t}-\beta_{t^{*}}-c}\right)^{2} \\
\frac{\partial \alpha}{\partial \beta_{j}}=\pi \rho_{j}\left[1-\left(\frac{c}{\beta_{t}-\beta_{t^{*}}-c}\right)^{2}\right]=\pi \rho_{j} \frac{\left(\beta_{j}-\beta_{t^{*}}\right)\left(\beta_{j}-\beta_{t^{*}}-2 c\right)}{\left(\beta_{j}-\beta_{t^{*}}-c\right)^{2}} \quad \forall j \geq t^{*}+1
\end{gathered}
$$

We can rewrite the partial derivative of the premium with respect to $\beta_{t^{*}}$ as a function of the $T-t^{*}$ other partial derivatives of the premium

$$
\frac{\partial \alpha}{\partial \beta_{t^{*}}}=\pi-\sum_{j=t^{*}+1}^{T} \frac{\partial \alpha}{\partial \beta_{j}}
$$

For simplicity, let

$$
\begin{aligned}
E U_{m}^{\prime}(.)= & (1-\pi) U^{\prime}(A-(1+m) \alpha)+\sum_{t=1}^{t^{*}} \pi \rho_{t} U^{\prime}\left(A-(1+m) \alpha-\lambda_{t}+\beta_{t^{*}}\right) \\
& +\sum_{t=t^{*}+1}^{T} \pi \rho_{t} U^{\prime}\left(A-(1+m) \alpha-\lambda_{t}+\beta_{t}\right)
\end{aligned}
$$

Making some substitutions and transformations of variables, (84) may be rewritten as

$$
\frac{\pi \sum_{t=1}^{t^{*}} \rho_{t} U^{\prime}\left(A-(1+m) \alpha-\lambda_{t}+\beta_{t^{*}}\right)}{(1+m) E U_{m}^{\prime}(.)}=\pi-\sum_{t=t^{*}+1}^{T} \frac{\partial \alpha}{\partial \beta_{t}}
$$

while (85) may be written as

$$
\frac{\pi \rho_{j} U^{\prime}\left(A-(1+m) \alpha-\lambda_{j}+\beta_{j}\right)}{(1+m) E U_{m}^{\prime}(.)}=\frac{\partial \alpha}{\partial \beta_{j}} \quad \forall j \geq t^{*}+1
$$

Combining these two equations yields

$$
\left[\begin{array}{c}
\sum_{t=1}^{t^{*}} \rho_{t} U^{\prime}\left(A-(1+m) \alpha-\lambda_{t}+\beta_{t^{*}}\right) \\
+\sum_{t=t^{*}+1}^{T} \rho_{j} U^{\prime}\left(A-(1+m) \alpha-\lambda_{t}+\beta_{t}\right)
\end{array}\right]=\frac{(1+m)(1-\pi)}{1-\pi(1+m)} U^{\prime}(A-(1+m) \alpha)
$$


What I want to show is that there exists a $m$ such that $\beta_{T}=\lambda_{T}$. The way I will proceed is to show that for some $m^{-}, \beta_{T}>\lambda_{T}$, for some other $m^{+}, \beta_{T}<\lambda_{T}$, and that $\frac{d \beta_{T}}{d m}<0$ over $m \in\left(m^{-}, m^{+}\right)$. At $m^{-}=0$, I showed in corollary 1 that $\beta_{T}>\lambda_{T}$. From (92) it is clear for $m^{+} \rightarrow \frac{1-\pi}{\pi}$ that $\beta_{T} \rightarrow 0$. All that now need to be shown is that $\frac{d \beta_{T}}{d m}$ is continuous in $m \in\left[0, \frac{1-\pi}{\pi}\right)$. Let us rewrite (92) as

$$
\begin{aligned}
\Phi= & \sum_{t=1}^{t^{*}} \rho_{t} U^{\prime}\left(A-(1+m) \alpha-\lambda_{t}+\beta_{t^{*}}\right)+\sum_{t=t^{*}+1}^{T} \rho_{j} U^{\prime}\left(A-(1+m) \alpha-\lambda_{t}+\beta_{t}\right) \\
& -\frac{(1+m)(1-\pi)}{1-\pi(1+m)} U^{\prime}(A-(1+m) \alpha)
\end{aligned}
$$
that

Using total derivatives, $\frac{d \beta_{T}}{d m}=-\frac{\frac{\partial \Phi}{\partial m}}{\frac{\partial \Phi}{\partial \beta_{T}}}$. Let us find $\frac{\partial \Phi}{\partial m}$ and $\frac{\partial \Phi}{\partial \beta_{T}}$. It is straightforward to show

$$
\begin{aligned}
\frac{\partial \Phi}{\partial m}= & -\alpha\left[\begin{array}{c}
\sum_{t=1}^{t^{*}} \rho_{t} U^{\prime \prime}\left(A-(1+m) \alpha-\lambda_{t}+\beta_{t^{*}}\right) \\
+\sum_{t=t^{*}+1}^{T} \rho_{j} U^{\prime \prime}\left(A-(1+m) \alpha-\lambda_{t}+\beta_{t}\right) \\
-\frac{(1+m)(1-\pi)}{1-\pi(1+m)} U^{\prime \prime}(A-(1+m) \alpha)
\end{array}\right] \\
& -\frac{(1-\pi)}{[1-\pi(1+m)]^{2}} U^{\prime}(A-(1+m) \alpha)
\end{aligned}
$$

and that

$$
\begin{aligned}
\frac{\partial \Phi}{\partial \beta_{T}}= & -(1+m) \frac{\partial \alpha}{\partial \beta_{T}}\left[\begin{array}{c}
\sum_{t=1}^{t^{*}} \rho_{t} U^{\prime \prime}\left(A-(1+m) \alpha-\lambda_{t}+\beta_{t^{*}}\right) \\
+\sum_{t=t^{*}+1}^{T} \rho_{j} U^{\prime \prime}\left(A-(1+m) \alpha-\lambda_{t}+\beta_{t}\right) \\
-\frac{(1+m)(1-\pi)}{1-\pi(1+m)} U^{\prime \prime}(A-(1+m) \alpha)
\end{array}\right] \\
& +\rho_{T} U^{\prime \prime}\left(A-(1+m) \alpha-\lambda_{T}+\beta_{T}\right)
\end{aligned}
$$

Clearly both $\frac{\partial \Phi}{\partial m}$ and $\frac{\partial \Phi}{\partial \beta_{T}}$ are negative since

$$
\begin{aligned}
0< & \sum_{t=1}^{t^{*}} \rho_{t} U^{\prime \prime}\left(A-(1+m) \alpha-\lambda_{t}+\beta_{t^{*}}\right)+\sum_{t=t^{*}+1}^{T} \rho_{j} U^{\prime \prime}\left(A-(1+m) \alpha-\lambda_{t}+\beta_{t}\right) \\
& -\frac{(1+m)(1-\pi)}{1-\pi(1+m)} U^{\prime \prime}(A-(1+m) \alpha)
\end{aligned}
$$

if (93) holds and $U^{\prime \prime \prime}()>$.0 . Therefore $\frac{d \beta_{T}}{d m}<0$ for all $m \in\left[0, \frac{1-\pi}{\pi}\right)$. This completes the proof.

Proof of corollary 2 The proof is similar to that of theorem 3. What I want to show is that there exists a $m$ such that $\beta_{t^{*}+1}=\lambda_{t^{*}+1}$. As before, I shall proceed by showing that for some $m^{-}$, $\beta_{t^{*}+1}>\lambda_{t^{*}+1}$, for some other $m^{+}, \beta_{t^{*}+1}<\lambda_{t^{*}+1}$, and that $\frac{d \beta_{t^{*}+1}}{d m}<0$ over $m \in\left(m^{-}, m^{+}\right)$. At $m^{-}=0$, I showed in corollary 1 that $\beta_{t^{*}+1}>\lambda_{t^{*}+1}$. From (92) it is clear for $m^{+} \rightarrow \frac{1-\pi}{\pi}$ that $\beta_{t^{*}+1} \rightarrow 0$. All that now needs to be shown is that $\frac{d \beta_{t^{*}+1}}{d m}$ is continuous in $m \in\left[0, \frac{1-\pi}{\pi}\right)$. I shall 
use (93) again. From theorem 3 we know that $\frac{\partial \Phi}{\partial m}<0$. It remains to be shown is that $\frac{\partial \Phi}{\partial \beta_{t^{*}+1}}<0$. $\frac{\partial \Phi}{\partial \beta_{t^{*}+1}}$ is given by

$$
\begin{aligned}
& \frac{\partial \Phi}{\partial \beta_{t^{*}+1}}=-(1+m) \frac{\partial \alpha}{\partial \beta_{t^{*}+1}}\left[\begin{array}{c}
\sum_{t=1}^{t^{*}} \rho_{t} U^{\prime \prime}\left(A-(1+m) \alpha-\lambda_{t}+\beta_{t^{*}}\right) \\
+\sum_{t=t^{*}+1}^{T} \rho_{j} U^{\prime \prime}\left(A-(1+m) \alpha-\lambda_{t}+\beta_{t}\right) \\
-\frac{(1+m)(1-\pi)}{1-\pi(1+m)} U^{\prime \prime}(A-(1+m) \alpha)
\end{array}\right] \\
&+\rho_{T} U^{\prime \prime}\left(A-(1+m) \alpha-\lambda_{t^{*}+1}+\beta_{t^{*}+1}\right)
\end{aligned}
$$

which is clearly negative if (93) holds and $U^{\prime \prime \prime}()>$.0 . Therefore $\frac{d \beta_{t^{*}+1}}{d m}<0$ for all $m \in\left[0, \frac{1-\pi}{\pi}\right)$. This completes the proof.•

Proof of corollary 3 The same as those of corollary 2 and theorem 3 .

$$
\begin{aligned}
\frac{\partial \Phi}{\partial \beta_{t^{*}}}= & -(1+m) \frac{\partial \alpha}{\partial \beta_{t^{*}}}\left[\begin{array}{c}
\sum_{t=1}^{t^{*}} \rho_{t} U^{\prime \prime}\left(A-(1+m) \alpha-\lambda_{t}+\beta_{t^{*}}\right) \\
+\sum_{t=t^{*}+1}^{T} \rho_{j} U^{\prime \prime}\left(A-(1+m) \alpha-\lambda_{t}+\beta_{t}\right) \\
-\frac{(1+m)(1-\pi)}{1-\pi(1+m)} U^{\prime \prime}(A-(1+m) \alpha)
\end{array}\right] \\
& +\sum_{t=1}^{t^{*}} U^{\prime \prime}\left(A-(1+m) \alpha-\lambda_{t^{*}}+\beta_{t^{*}}\right)
\end{aligned}
$$

This is negative if (93) holds and $U^{\prime \prime \prime}()>$.0 . Therefore $\frac{d \beta_{t^{*}}}{d m}<0$. This completes the proof.

\section{TABLE 1}

Beliefs of the insurer in equilibrium.

\begin{tabular}{|c|c|c|c|c|c|c|c|c|}
\hline $\begin{array}{c}\text { Belief the real } \\
\text { loss is equal to }\end{array}$ & $\lambda_{1}$ & $\lambda_{2}$ & $\ldots$ & $\lambda_{t^{*}-1}$ & $\lambda_{t^{*}}$ & $\lambda_{t^{*}+1}$ & $\ldots$ & $\lambda_{T}$ \\
\hline Reported loss & & & & & & & & \\
\hline$\lambda_{1}^{\prime}$ & 1 & 0 & 0 & 0 & 0 & 0 & 0 & 0 \\
\hline$\lambda_{2}^{\prime}$ & 0 & 1 & 0 & 0 & 0 & 0 & 0 & 0 \\
\hline$\ldots$ & 0 & 0 & 1 & 0 & 0 & 0 & 0 & 0 \\
\hline$\lambda_{t^{*}-1}^{\prime}$ & 0 & 0 & 0 & 1 & 0 & 0 & 0 & 0 \\
\hline$\lambda_{t^{*}}^{\prime}$ & 0 & 0 & 0 & 0 & 1 & 0 & 0 & 0 \\
\hline$\lambda_{t^{*}+1}^{\prime}$ & 0 & 0 & 0 & 0 & $1-\gamma_{t^{*}+1}$ & $\gamma_{t^{*}+1}$ & 0 & 0 \\
\hline$\ldots$ & 0 & 0 & 0 & 0 & $1-\gamma_{\ldots}$ & 0 & $\gamma_{\ldots}$ & 0 \\
\hline$\lambda_{T}^{\prime}$ & 0 & 0 & 0 & 0 & $1-\gamma_{T}$ & 0 & 0 & $\gamma_{T}$ \\
\hline & where $\gamma_{t}=\frac{\beta_{t}-\beta_{t^{*}-c}}{\beta_{t}-\beta_{t^{*}}} \forall t>t^{*}$ & & \\
\hline
\end{tabular}




\section{Liste des publications au CIRANO*}

Série Scientifique / Scientific Series (ISSN 1198-8177)

2001s-29 Project Financing when the Principal Cannot Commit / M. Martin Boyer

2001s-28 Complementarities in Innovation Policy / Pierre Mohnen et Lars-Hendrick Röller

2001s-27 Bankruptcy Cost, Financial Structure and Technological Flexibility Choices /

Marcel Boyer, Armel Jacques et Michel Moreaux

2001s-26 Inflation as a Strategic Response / M. Martin Boyer et Pierre Thomas Léger

2001s-25 Simulation-Based Finite-Sample Tests for Heteroskedasticity and ARCH Effects / Jean-Marie Dufour, Lynda Khalaf, Jean-Thomas Bernard et Ian Genest

2001s-24 The Role of Organizational Commitment and Citizenship Behaviors in Understanding Relations between Human Resources Practices and Turnover Intentions of IT Personnel / Guy Paré, Michel Tremblay et Patrick Lalonde

2001s-23 A Resource-Based Analysis of Outsourcing: Evidence from Case Studies / Vital Roy et Benoit Aubert

2001s-22 Short and Long Memory in Equilibrium Interest Rate Dynamics / Jin-Chuan Duan et Kris Jacobs

2001s-21 Unemployment Insurance and Subsequent Job Duration: Job Matching vs Unobserved Heterogeneity / Christian Belzil

2001s-20 Estimating the Intergenerational Education Correlation from a Dynamic Programming Model / Christian Belzil et Jörgen Hansen

2001s-19 The Bootstrap of the Mean for Dependent Heterogeneous Arrays / Sílvia Gonçalves et Halbert White

2001s-18 Perspectives on IT Outsourcing Success: Covariance Structure Modelling of a Survey of Outsourcing in Australia / Anne C. Rouse, Brian Corbitt et Benoit A. Aubert

2001s-17 A Theory of Environmental Risk Disclosure / Bernard Sinclair-Desgagné et Estelle Gozlan

2001s-16 Marriage Market, Divorce Legislation and Household Labor Supply / Pierre-André Chiappori, Bernard Fortin et Guy Lacroix

2001s-15 Properties of Estimates of Daily GARCH Parameters Based on Intra-Day Observations / John W. Galbraith et Victoria Zinde-Walsh

2001s-14 A Ricardian Model of the Tragedy of the Commons / Pierre Lasserre et Antoine Soubeyran

2001s-13 Carbon Credits for Forests and Forest Products / Robert D. Cairns et Pierre Lasserre

* Consultez la liste complète des publications du CIRANO et les publications elles-mêmes sur notre site Internet : 